\title{
Hacia una gobernanza de las áreas marinas protegidas. Estado de la cuestión $y$ algunos retos a vencer ${ }^{1}$
}

\author{
Blanca Soro Mateo \\ Profesora Titular de Derecho Administrativo \\ Universidad de Murcia
}

SUMARIO.- I. CONSIDERAGIONES PREVIAS: LA TARDÍA PREOCUPACIÓN POR LA PROTECGIÓN DEL MEDIO MARINO. II. PRINCIPIOS BÁSICOS PARA LA GOBERNANZA DE LAS AMPS. ALGUNAS PROPUESTAS. 1. El principio de coordinación exige una reclasificación de las AMPs. 2. El principio de integración exige el reconocimiento del carácter prevalente de los planes de gestión de las AMPs. 3. El principio de participación como elemento fundamental de la Gobernanza de las AMPs. III. GOBERNANZA DE ÁREAS MARINAS. 1. Consideraciones previas sobre la privatización de funciones públicas. 2. Primeros pasos: de la participación del público en la protección de los espacios naturales. 3. La gobernanza de áreas marinas en el ordenamiento jurídico español: el silencio del término por parte de la LPMM. IV. MODELOS DE GOBERNANZA APLICABLES AL MEDIO MARINO. 1. Gestión integrada de zonas costeras como modelo de gobernanza: planificación integral y participada. A. La gestión integrada de zonas costeras (GIZC) en España. La conveniente integración de los espacios naturales marinos en su ámbito territorial. B. Posible esquema normativo para la implantación del modelo de gestión integrada de las zonas costeras propuesto por el prof.Sanz Larruga. 2. Los convenios de colaboración en el ámbito de gestión de las áreas marinas. 3. La custodia del territorio aplicada al medio marino. Su inacabado

\footnotetext{
$1 \quad$ El presente estudio trae causa en la comunicación defendida en el XIII Coloquio Luso-Español de Profesores de Derecho Administrativo celebrado en la Coruña y Santiago de Compostela los días 26 y 27 de octubre de 2018. Ha sido realizado en el marco del Proyecto de Investigación titulado "Bioderecho ambiental y protección de la vulnerabilidad: hacia un nuevo marco jurídico" (Referencia: DER2017-85981C2-1-R), Ministerio de Ciencia, Innovación y Universidades (Convocatoria 2017 de Proyectos de I+D+i correspondientes al Programa estatal de Investigación, Desarrollo e Innovación orientada a los Retos de la Sociedad, en el marco del Plan Estatal de Investigación Científica y Técnica y de Innovación 2013-2016), IP: Dra. Blanca Soro Mateo (Universidad de Murcia) y Dr. José Francisco Alenza García (Universidad Pública de Navarra).

Recibido: 30/05/2019

Aceptado: 20/09/2019
} 
diseño en la LPNB. V. CUSTODIA MARINA. 1. Concepto y reflexiones sobre los retos adicionales que plantea la custodia aplicada al medio marino. 2. Análisis de un caso: las Marismas de Alday. La concesión como título habilitante. 3. Propuesta conclusiva: adicionalidad y necesidad de garantizar la concurrencia en las concesiones de dominio público marítimo-terrestre como título habilitante para la custodia marina

RESUMEN: El presente estudio quiere compartir algunas reflexiones del análisis sobre marco jurídico de la gobernanza de las áreas marinas protegidas, como parte de un estudio interdisciplinar consistente en la elaboración de una Estrategia de gobernanza para los espacios marinos de la Red Natura 2000 en el marco del Proyecto LIFE INDEMARES. Una vez detectados los retos a los que se enfrenta la gobernanza de las áreas marinas se plantean propuestas de lege ferenda para la mejor ordenación del espacio marítimo, teniendo en cuenta la necesaria coordinación entre la implementación de los instrumentos jurídicos contemplados en la normativa reguladora de las AMPS con los derivados de la normativa sobre recursos y actividades que se desarrollan en el mar, todo ello en el marco de la más omnicomprensiva Política Marítima Europea reguladora de la ordenación del espacio marítimo.

PALABRAS CLAVE: gobernanza, áreas marinas protegidas, ordenación del espacio marítimo, custodia marina

ABSTRACT: This study analyzes the legal framework of the governance of marine protected areas. The challenges facing the governance of marine areas are detected and proposals of lege ferenda are proposed for the better management of maritime space. The necessary coordination between the implementation of the legal instruments contemplated in the regulatory regulations of the AMPS and the legal instruments derived from the regulations on marine resources and activities carried out at sea, within the framework of the most omnicomprensive European Maritime Policy regulating the management of maritime space.

KEYWORDS: governance, marine protected areas, maritime space management, marine custody

\section{LA TARDÍA PREOGUPAGIÓN POR LA PROTEGGIÓN DEL ME- DIO MARINO}

La preocupación por la protección del medio marino ha sido mucho más tardía que en el caso terrestre, retraso temporal que felizmente ha culminado con el establecimiento de áreas marinas protegidas (AMPS) y que nos permite contar ahora con la experiencia ordenadora del medio terrestre. Esta herramienta de gestión ha comenzado a desarrollarse en los últimos años, sin menoscabo del mantenimiento de 
otras figuras contempladas en la normativa sectorial, como las reservas marinas de interés pesquero o las áreas especiales para la navegación.

En una primera aproximación, puede afirmarse que las AMPS son espacios marinos protegidos en los que existen limitaciones -que pueden llegar a la prohibición- de diferentes usos y actividades que se proyectan sobre el mar (navegación, pesca, actividades deportivas y de ocio, pesca de bajura, acuicultura, prospección y explotación de recursos naturales, parques de energía eólica marina, entre otras. Esta coexistencia de actividades en el mar hace que, en el plano competencial, además de concurrir diversos ámbitos institucionales desde los que se aborda la política de protección ambiental del medio marino, y dada nuestra compleja y vertebrada distribución de competencias, concurran competencias sobre diversas materias que convocan al Estado y a las CGAA y que dificultan una gestión integradora adecuada del medio marino.

Al igual que en el ámbito terrestre, la coexistencia de actividades sobre un mismo espacio exige que las figuras de protección de espacios naturales vayan acompañadas de un plan de gestión en el que se concreten y ordenen los usos y aprovechamientos de recursos admitidos en el espacio, con la finalidad última de asegurar que éstos se llevan a cabo de modo sostenible y que resultan compatibles con los objetivos de conservación del espacio protegido. La zonificación, acompañada de la planificación, como técnicas de protección ambiental de los espacios naturales en general, constituyen dos herramientas de protección ambiental que facilitan y permiten la consecución de los objetivos de conservación.

Partiendo de la experiencia adquirida en la gestión de los espacios naturales terrestres y una vez consolidada la categoría de AMP como figura específica de protección de espacios naturales marinos, consideramos conveniente llevar a cabo una reflexión sobre la necesidad de una más acabada articulación de los instrumentos de gestión existentes y de una mejor coordinación con el resto de políticas que inciden en el mar, haciendo un especial esfuerzo en el reforzamiento de la participación, la transparencia y el buen gobierno de las AMP, en el en el sentido de incorporar instrumentos participativos en todas las fases de protección, y no sólo en el procedimiento de elaboración de los planes de gestión, pero sobre todo a la hora de poner en marcha la gestión, como exigencia del Convenio de Aarhus.

Uno de los fundamentales retos se circunscribe a la necesidad de integrar todo el arsenal normativo tuitivo de las AMPS en el paquete normativo creado para la ordenación del espacio marítimo en el marco de la Política Marítima Integrada y que, en el ámbito marino, ha venido identificándose como "Crecimiento Azul". En este sentido, la Directiva 2014/89/UE tiene por objeto, trascendiendo la finalidad tuitiva del régimen jurídico ambiental de las AMPS, el crecimiento sostenible de 
las economías y de los espacios marítimos y en el aprovechamiento sostenible de los recursos marinos ${ }^{2}$.

\section{PRINCIPIOS BÁSICOS PARA LA GOBERNANZA DE LAS AMPS. ALGUNAS PROPUESTAS}

\section{El principio de coordinación exige una reclasificación de las AMPs}

La coordinación se erige como como principio esencial cuando coexisten sobre un mismo espacio físico distintas instancias competentes o políticas con distinta finalidad, coordenadas que, sin duda, se cumplen en el ámbito de las AMPS, dada la complejidad competencial que afecta a las mismas y que deriva, en parte, de su naturaleza demanial, pero fundamentalmente porque sobre ellas se proyectan competencias normativas y de gestión estatales y autonómicas como consecuencia del reparto interno de competencias sobre medio marino, protección del medio ambiente y espacios naturales protegidos, sin obviar la compleja articulación de estos sectores materiales ambientales con otros títulos competenciales conexos que se proyectan sobre el mismo espacio físico marítimo. En suma, hablar de AMPS en un Estado vertebrado como el autonómico y europeo exige la compleja tarea de coordinación de todo el arsenal normativo comunitario, estatal y autonómico que regula la protección de las AMPS con la normativa general sobre protección de la biodiversidad que también resulta de aplicación a las AMPS -al contemplar instrumentos jurídicos puestos también al servicio de la protección del medio marino- y con el derecho de aguas y de ordenación del espacio marítimo³.

Si bien se han detectado algunas fortalezas, derivadas del impulso en la protección del medio marino como consecuencia de las obligaciones derivadas de la Directiva hábitat, de la existencia de una figura de protección ad hoc y del carácter integrador de las Estrategias marinas, sin embargo, son más numerosas las debilidades y los retos planteados. Por resaltar algunos de ellos, destacamos la confusión que genera la posibilidad de utilizar el resto de figuras contempladas en la LPNB

2 Por otra parte, en el plano internacional, la Agenda 2030 para el Desarrollo Sostenible incluye como OCD 14 "Conservar y utilizar sosteniblemente los océanos, los mares y los recursos marinos para el desarrollo sostenible".

3 Nos referimos a las normas relativas a la protección ambiental del medio marino, y concretamente las Directivas hábitat y Aves y la LPNB, la Directiva sobre la Estrategia marina, la LPMM y la DMA y el TRLA - por afectar a las aguas de transición y costeras-, con la Política Marítima Integrada y su desarrollo mediante la Directiva 2014/89/UE y el Real Decreto 363/2017, de 8 de abril sobre ordenación del espacio marítimo, como política que debe integrar la triple perspectiva ambiental, social y económica del desarrollo sostenible del mar. 
para proteger el medio marino, la posibilidad de coexistencia de planes de gestión diversos sobre el mismo área, con los consiguientes problemas de prevalencia en caso de conflicto, la falta de coincidencia entre la superficie de los LIC-ZEPAS-ZEC y las AMPS, la situación transitoria en la que se encuentran los LIC marinos hasta que no se declaren las ZEC y se aprueben los Planes de gestión, las dificultades de coordinación con la Directiva Marco de Aguas, las imprecisiones sobre las relaciones de los planes de gestión de las AMPS con otros entre planes que inciden en el mar y la carencia de información cartográfica completa de las concesiones de dominio público marítimo-terrestre vigentes.

Proponemos, en este orden de cosas, además de una normalización internacional de figuras, limitar el resto de figuras de protección contempladas en la LPNB al medio terrestre y reservar la figura de AMP para el marino en todo caso, lo cual requiere una reclasificación de las preexistentes, un reajuste de los límites de las AMPS a los LIC marinos y el establecimiento de un carácter prevalente y determinante de los planes de gestión de las áreas marinas, en los términos en que se diseñan los PORN por la LPNB.

\section{El principio de integración exige el reconocimiento del carácter prevalente de los planes de gestión de las AMPs}

En segundo término, y en relación con la coexistencia de diversos usos e intereses que se dan en el medio marino al que se circunscriben las AMPS, otro principio fundamental que debe inspirar la gobernanza de las AMPS es el de integración. Aunque es a la Política Marítima Europea a la que se atribuye esta función de integración de las políticas ambientales, sociales y económicas en el medio marino, la gobernanza de las AMPS debe incorporar también el enfoque de lo que ha venido en denominarse GIZC ${ }^{4}$.

La doctrina ya ha puesto de manifiesto algunas incoherencias ${ }^{5}$, teniendo en cuenta que el ámbito espacial de aplicación de los Planes de ordenación del espacio

$4 \quad$ La Gestión Integrada de zonas costeras de Europa fue objeto de una Estrategia Europea que tiene por finalidad "conseguir equilibrar a largo plazo, dentro de los límites impuestos por la dinámica natural y la capacidad de carga de la zona, los beneficios del desarrollo económico y de los usos de la zona costera por los seres humanos, de la protección, preservación y restauración de las zonas costeras, de la reducción de las pérdidas en términos de vidas humanas y de daños a las cosas y del acceso y disfrute públicos de la costa". También en dicha lógica, es necesario aludir a la "Política marítima integrada", que abarca como pilar ambiental la Directiva sobre la estrategia marina, pero que incluye, además de objetivos ambientales, otros que tiene más que ver con la planificación de la actividad económica en el mar, y con el fomento del crecimiento sostenible de las economías marítimas.

5 Así, en sede de exclusiones, el art. 2.2 del Real Decreto 363/2017, por el que se establece un Marco para la Ordenación del Espacio Marítimo (ROEM) se refiere a la ordenación del territorio y el urbanismo y el litoral. SANZ LARRUGA considera que su exclusión no parece del todo acertada "por la necesidad de promover con la misma la coherencia del plan o planes de ordenación del espacio marítimo resultantes con otros procesos 
marítimo (POEM) y de las Estrategias marinas (EM) es el mismo, aunque la vocación de los POEM es más amplia que la de las EM, pues aquellos tienen por objeto la ordenación del espacio marítimo en su conjunto, con una finalidad ambiental económica y social. Puede concluirse que la transposición de la Directiva 2014/89/ UE al ordenamiento jurídico español no garantiza una adecuada coordinación entre las competencias estatales y autonómicas concurrentes en el medio marino.

En sede participativa, el art. 8.2 del ROEM establece expresamente que se velará por que los grupos de interés y autoridades pertinentes, así como el público afectado, tengan acceso a los planes una vez concretados, mediante la publicación del contenido de los mismos, incluida la parte no normativa no aprobada como RD, en la web del Ministerio de Agricultura y Pesca, Alimentación y Medio Ambiente. Dos precisiones, a nuestro juicio, requiere dicho precepto. Primero, debería haberse referido a Administraciones competentes y no "pertinentes". Segundo, se habla de concreción del plan y no de aprobación y se da por hecho que parte de los POEM tendrán carácter no normativo (sic) y que, en consecuencia, no serán objeto de publicación oficial. Debe tenerse en cuenta que la participación que contempla el precepto se traduce en transparencia o publicidad activa, no en participación en el procedimiento de elaboración de los POEM. Ello contrasta con el carácter normativo, determinante y prevalente de los PORN, que postulamos deberían positivarse como obligatorios en relación a las AMPS, y otros planes cuyo contenido pretende integrar la PMI.

pertinentes, y por la necesidad de tener en cuenta la interacción tierra mar SANZ LARRUGA, J., "La nueva ordenación del espacio marítimo: Análisis del Real Decreto 363/2017, de 8 de abril”, Práctica urbanística, núm. 150, La Ley 275/2018, pp. 8 y 9. En el mismo sentido MENÉNDEZ REXACH señaló que se debe asegurar la coordinación con los planes de ordenación del litoral y demás instrumentos para la gestión integrada de las zonas costeras, entre ellos, los planes hidrológicos de demarcación. Por otra parte, en relación con los POEM, MENÉNDEZ REXACH advierte del carácter integrador, flexible y estratégico de los POEM, los cuales, a su juicio, deben integrar a la planificación sectorial sin pretender sustituirla, esto es sin desplazar la función ordenadora de los planes contemplados en la legislación propia de cada sector, añadiendo que "sus determinaciones deben consistir más en directrices y recomendaciones que en normas de directa aplicación (MENENDEZ REXACH, A., "La ordenación del espacio marítimo", en NÚÑEZ LOZANO, M. C., Estudios jurídicos sobre el litoral, Tirant lo Blanch, Valencia 2016, pp. 46 y ss.). Por otra parte, por lo que se refiere a la competencia estatal para la aprobación del POEM, SANZ LARRUGA estima criticable que se atribuya la competencia para la aprobación del Plan al Consejo de Ministros, porque ello supone reconocer un excesivo protagonismo al Estado cuando en la ordenación del espacio marítimo confluyen muchas e importantes competencias de las CCAA e incluso de los municipios. Por su parte, MENÉNDEZ REXACH ve lógico que se atribuya protagonismo al Ministerio de medio ambiente, aunque deberían haberse incluido a los departamentos de las CGAA con competencias en medio ambiente, por la existencia de continuidad ecológica del ecosistema marino, proponiendo la constitución de un Comité de autoridades competentes similar al existente en materia de aguas en el ámbito de cada Demarcación hidrográfica (SANZ LARRUGA, J., Ibidem, p. 13, 16 y ss. y MENÉNDEZ REXACH, Ibidem, p. 47). 
Por otra parte, si bien para la aprobación de las EM la LPMM ha contemplado la participación las $\mathrm{CAAA}^{6}$, no se ha previsto la participación de las mismas en el procedimiento de elaboración de los POEM, cuando estos tienen un ámbito mucho más amplio y afectan a una multitud de competencias autonómicas ambientales y no ambientales.

Como propuestas en este ámbito propugnamos, además de la conveniente participación de las CGAA en la elaboración de los POEM, el establecimiento del carácter determinante y prevalente de los planes de gestión de las AMPS sobre la planificación integral del medio marino y el resto de planificación sectorial que incide sobre el mar. Asimismo, debería establecerse una reserva de Administración para la declaración de los espacios naturales en general, como se ha llevado a cabo en la LPMM respecto de las AMPS de competencia estatal, con el fin de evitar la utilización del vehículo formal de ley para la eventual declaración de una AMPS por parte de las CCAA.

\section{El principio de participación como elemento fundamental de la Gobernanza de las AMPs}

En tercer lugar, una verdadera Gobernanza de las AMPS debe también cumplir las exigencias de la participación pública, no sólo en el procedimiento de elaboración de sus planes de gestión. La participación pública se erige como un elemento fundamental de la perseguida gobernanza de las AMPS, que debe trascender la también necesaria participación ciudadana, para alcanzar, además, la implicación de las poblaciones locales en los proyectos de conservación, valorización y desarrollo del medio marino. En dicha lógica, se han constatado previsiones sobre participación en los procedimientos de elaboración de las EM, en su evaluación ambiental y en el resto de políticas relacionadas con el medio marino.

Tradicionalmente la declaración y gestión de los ENP ha sido una tarea exclusivamente pública, aunque comienzan a observarse tímidos avances hacia la gestión privada $^{7}$. No obstante, la regulación de las garantías e instrumentos de participación

6 Las EM serán aprobadas por el Gobierno mediante Real Decreto (reserva de Administración), previo debate en el seno de la Conferencia Sectorial de Medio Ambiente, y previo informe de los Ministerios afectados, las Comunidades Autónomas afectadas, y del Consejo Asesor de Medio Ambiente, una vez cumplido el trámite de información pública

7 Así la reciente LPN de 2015, de la LPN apela a la participación pública e implicación en la organización y gestión de los parques nacionales (art. 35) "Los parques nacionales deben constituir, en su forma de organización y gestión, un referente general de participación pública e implicación social. Las actividades de gestión deberán primar la integración de los municipios afectados, sectores y colectivos, y conformarse como un instrumento para la cohesión territorial de las áreas en donde están situados. En particular se prestará especial atención a la implicación social, a la participación de los municipios afectados en la toma de decisiones y al apoyo singularizado a las poblaciones locales residentes en el interior de los parques nacionales". 
en la LPNB y en la LPMM resulta modesta y se limita, a salvo la escasa referencia a la custodia del territorio, a los clásicos derechos a formular alegaciones y participación en el trámite de audiencia ${ }^{8}$.

Como propuestas en este ámbito, además del reconocimiento de la iniciativa particular para la declaración de espacios naturales y, en nuestro caso, de AMPS en la LPNB y en la LPMM, postulamos el establecimiento de una reserva de Administración para la declaración y desclasificación de AMPS y convenimos en la necesidad de la regulación de la revisión de la declaración de AMPS cuando resulte competentes las CGAA como consecuencia de estudios sobrevenidos que justifiquen su competencia.

Asimismo, es necesario concretar la coordinación interadministrativa y entre AAPP territoriales en el ámbito de las AMPS autonómicas. Además, en la línea de las Recomendaciones de la UICN, deben ser explorados algunos modelos de gobernanza aplicables al medio marino como la $\mathrm{GIZC}^{9}$, los eventuales espacios marinos de interés particular, los convenios de colaboración para la gestión integral del litoral

8 El art. 3.c) de la LPACAP reconoce capacidad de obrar ante las Administraciones públicas a los «grupos de afectados, las uniones y entidades sin personalidad jurídica y los patrimonios independientes o autónomos», abriendo la puerta a la tutela de los intereses colectivos o difusos en nuestro procedimiento administrativo.

9 Desde el V Congreso de la UICN celebrado en Durban, en 2003 bajo el título «Beneficios más allá de las fronteras» la UICN proponía la asunción de principios inspiradores de la gestión tales como la descentralización, la participación, la transparencia y la responsabilización de las comunidades locales. En su Recomendación n. 25 «Cogestión de las áreas protegidas» surgida del congreso de Durban, la UICN llegó a acuñar el concepto de «áreas protegidas coadministradas», como espacios (en los que «la autoridad, la responsabilidad y la rendición de cuentas de la gestión están repartidas entre dos o más interesados directos, por ejemplo, órganos u organismos gubernamentales de diversos niveles, comunidades (...) locales, organizaciones no gubernamentales y agentes privados...». Tanto la doctrina (BARRAGÁN MUÑOZ y SANZ LARRUGA) como diversos organismos, vienen proponiendo desde hace décadas diversos modelos de GIZC a partir del análisis geográfico y de la ordenación del territorio, analizando las peculiaridades geográficas, económicas y administrativas del litoral, para ofrecer finalmente diversas recomendaciones y orientaciones metodológicas para la ordenación y planificación del litoral como espacio "polidisputado". En España, la GIZC se encuentra con una adicional dificultad derivada de la compleja distribución de competencias, que complica, su aplicación. No obstante, las CCAA desde hace décadas, han liderado importantes iniciativas de carácter normativo que adoptan la perspectiva de la gestión integrada del litoral. Como la ya derogada Ley murciana 3/1987, de 23 de abril, de "Protección y Armonización de Usos del Mar Menor", las Directrices Regionales del Litoral de Andalucía, aprobadas por Decreto 118/1990, de 17 de abril, el Plan de Mejora Ambiental del Litoral de Andalucía (1995-2000), las Directrices Subregionales de Ordenación del Territorio para la Franja Costera del Principado de Asturias", aprobadas por Decreto 107/1993, de 16 de diciembre, los Planes de Ordenación del Litoral de la Comunidad Autónoma de Baleares, aprobados por Decreto 72/1994, de 26 de mayo), la Ley 4/1998 de "Protección del Cap de Creus" de la Comunidad Autónoma de Cataluña, entre otras. En la Región de Murcia, aunque se encuentra paralizada por la oposición de diversos sectores económicos, se hizo público hace unos meses el Avance de la Estrategia de Gestión Integrada de Zonas Costeras del Sistema Socio-Ecológico del Mar Menor y su Entorno (SSEMM). 
y la custodia marina, como técnica jurídica de componente privado para la gestión de las AMPS.

\section{LA GOBERNANZA DE AREAS MARINAS: CONTEXTUALIZA- CIÓN}

\section{Consideraciones previas sobre la privatización de funciones públicas}

La correlación entre lo público y lo privado en el ámbito del Derecho Público se encuentra en constante evolución en función de las circunstancias sociales y sobre todo políticas y económicas de cada momento. Además, se trata de una cuestión que también viene determinada por las posiciones ideológicas y doctrinales dominantes. En España, en el contexto actual de recomposición de las relaciones Estado-Sociedad al que se refiere ESTEVE PARDO ${ }^{10}$, están gestándose nuevos modos de actividad de la Administración. Mas, estas nuevas modalidades de intervención no acaban, sin embargo, con los tradicionales modos de actividad que desde antaño conforman lo que se ha venido en denominar actividad material de la Administración (servicio público, policía y fomento), sino que se mantienen y coexisten con esas nuevas fórmulas de gestión. Nos referimos, como nuevas modalidades de actividad pública, en general, a la privatización generalizada que incorpora al panorama jurídico a las entidades colaboradoras, a las discutibles fórmulas privadas de control de riesgos, a la privatización de los servicios públicos o de su gestión, a las recientes comunicaciones previas y declaraciones responsables, a la actividad de regulación propia del nuevo modelo de Estado garante -que trasciende el tradicional Estado policial o de intervención- $\mathrm{y}$, en general, a la cogestión y a la custodia del territorio como fórmulas de gestión privada de intereses públicos.

Como fundamentos de esta privatización de funciones públicas pueden encontrarse diversos principios muy en boga en los últimos tiempos, mínima intervención, corresponsabilización, eficiencia, eficacia, sostenibilidad, agilidad, participación y control entre otros.

Así, por un lado, por lo que se refiere a la actividad de intervención, que se materializa tradicionalmente en licencias, autorizaciones y concesiones, la incorporación de la comunicación previa y de la declaración responsable al elenco de títulos habilitantes para el ejercicio de actividades, auspiciada por políticas de liberalización de actividades, supone un importante riesgo para la garantía del cumplimiento del derecho ambiental y una desresponsabilización de la Administración en relación a

10 Manual de Derecho Administrativo, Marcial Pons, 2017, p. 353. 
un importante número de sectores de actividad. En el ámbito del servicio público, y apelando a la mayor eficacia y eficiencia de la gestión privada, asistimos a una oleada de privatizaciones que, si bien pudiera resultar adecuada en el ámbito de los servicios públicos de contenido económico, no encuentra, en cambio, igual justificación en el ámbito de los servicios públicos de contenido social, y supone, sin lugar a dudas, un retroceso del Estado social. En fin, por lo que se refiere al desarrollo de políticas públicas en las que se materializa el deber de las AAPP de preservar el medio ambiente o función pública ambiental, y especialmente en sede de conservación de la naturaleza, el fundamento de la privatización de dicha función se ha querido encontrar en el principio de participación.

Puede decirse, a priori, que la generalización de los instrumentos privados de gestión de la biodiversidad natural o restaurada como resultado de un proceso de recuperación de los daños entraña ciertos peligros, como la privatización de las políticas públicas, caldo de cultivo de la corrupción. Mas lo cierto es que es necesario explorar las ventajas de estos instrumentos respecto de la conservación pasiva, analizándose cuidadosamente los límites a que debe someterse el desarrollo de estas herramientas de gestión para garantizar el cumplimiento del Derecho ambiental y la indemnidad de los derechos. Los instrumentos voluntarios y de mercado dirigidos a colaborar en la protección y conservación de la Biodiversidad, así como la desregulación como tendencia generalizada en gran parte de los ámbitos de acción pública se van abriendo paso paulatinamente traspasando las fronteras del Derecho ambiental y, en especial, del derecho de la Biodiversidad. Estas "nuevas" herramientas, deben conservar su carácter complementario del instrumental tradicional de conservación de la biodiversidad.

\section{Primeros pasos: de la participación del público en la protección de los espacios naturales}

Tradicionalmente la declaración y gestión de los ENP ha sido una tarea exclusivamente pública. Sin embargo, en la actualidad puede afirmarse que los actores privados cada vez desempeñan un papel más importante en este ámbito. Así, ONG, voluntariado o incluso empresas privadas y usuarios, entre otros agentes, a través de diversas fórmulas jurídicas comparten con las AAPP la general tarea de conservación de los EENN.

Por su proximidad al territorio, y comunidad de intereses, los residentes de los espacios naturales protegidos y las poblaciones adyacentes pueden contribuir muy positivamente a la conservación de los espacios naturales protegidos. Así lo aconsejan los principios de colaboración, coordinación y cooperación. En este sentido resulta paradigmático el art. 35 de la LPN al disponer que "Los parques nacionales deben constituir, en su forma de organización y gestión, un referente general de participación pública 
e implicación social. Las actividades de gestión deberán primar la integración de los municipios afectados, sectores y colectivos, y conformarse como un instrumento para la cohesión territorial de las áreas en donde están situados. En particular se prestará especial atención a la implicación social, a la participación de los municipios afectados en la toma de decisiones y al apoyo singularizado a las poblaciones locales residentes en el interior de los parques nacionales". La participación social en la organización y gestión de los parques nacionales se convierte, por lo tanto, en un fin en sí misma.

Esta concepción, calificada por BERMEJO LATRE como manifiestamente política de los espacios naturales protegidos surge, a su juicio, de un marco teórico que a su vez es soportado por, o ha dado lugar a, importantes documentos jurídicos a escala internacional. Así,

"En el plano vinculante se han de evocar nuevamente los citados Principios X y, sobre todo esta vez, XXII de la Declaración de Río de Janeiro de 1992. En el plano del soft law cabe aludir a la Unión Internacional para la Conservación de la Naturaleza como organización promotora no solo de la participación social en la gestión, sino incluso de la gestión compartida o «cogestión», de los espacios naturales protegidos, lo que viene a ser el máximo exponente de la gobernanza medioambiental. Desde el V Congreso de la UICN celebrado en Durban en 2003 bajo el título «Beneficios más allá de las fronteras» se viene advirtiendo la necesidad de distribuir equitativamente los beneficios y costes de la conservación de los espacios naturales, normalmente desequilibrados (socialización de beneficios frente a localización de costes). A tal efecto, la creación de consorcios, y, últimamente, los contratos territoriales; y (vi) la cogestión plantea algunos retos técnicos no menores, tales como la definición de los ámbitos territorial, material, funcional y financiero de la cogestión (competencias y potestades retenidas y delegadas, alcance de la coordinación administrativa y extensión de las responsabilidades económicas).

UICN proponía la asunción de principios inspiradores de la gestión tales como la descentralización, la participación, la transparencia y la responsabilización de las comunidades locales. En su Recomendación n. 25 «Cogestión de las áreas protegidas» surgida del congreso de Durban, la UICN llegó a acuñar el concepto de «áreas protegidas coadministradas», como espacios (de las Categorías I a VI, entre las que se cuentan nuestros espacios naturales protegidos) en los que «la autoridad, la responsabilidad y la rendición de cuentas de la gestión están repartidas entre dos o más interesados directos, por ejemplo órganos u organismos gubernamentales de diversos niveles, 
comunidades (...) locales, organizaciones no gubernamentales y agentes privados...».

En la Recomendación se pretende asegurar la participación de los interesados directos en la adopción de decisiones relativas «al establecimiento y la gestión de las áreas protegidas». Dicha participación se cifra en el reparto de la autoridad, las responsabilidades, los beneficios y los costos de la gestión de las áreas protegidas entre los actores implicados, en virtud de procesos de negociación previos encaminados a la definición de las responsabilidades. Asimismo, se reprocha que los esfuerzos desplegados para incorporar a las comunidades locales en la gestión de las áreas protegidas se limiten a las consultas, la petición de ayuda para ejecutar actividades preestablecidas o la distribución de algunos beneficios derivados de la explotación de los espacios naturales protegidos, pero no relacionados con los costes de la explotación, sin los previos y necesarios procesos eficaces de discusión y negociación de las opciones.

La cogestión de espacios naturales protegidos («conservación de áreas administradas eficazmente en régimen de cogestión y gestión comunitaria», según los propios términos de la Recomendación) es contemplada como una de las más eficaces modalidades para movilizar los recursos dedicados a la conservación ambiental, que están a disposición de las comunidades y de los gobiernos locales, las organizaciones no gubernamentales y el sector privado. La UICN confía en la cogestión para lograr una distribución más eficaz y transparente del poder de decisión y una participación más activa e importante de las comunidades locales en la gestión de las áreas protegidas, y a una mejor sinergia de las capacidades de conservación. Así pues, la Recomendación advierte de la necesidad de poner en marcha procesos de cogestión, previa la negociación de acuerdos y el establecimiento de las organizaciones que resulten necesarias. En concreto, pretende la creación o refuerzo de los marcos jurídicos y de las políticas que favorezcan la cogestión de las áreas protegidas; la promoción del examen, consolidación, fortalecimiento y la ampliación de las actuales experiencias de cogestión de áreas protegidas; la potenciación de las actividades de investigación y acción en áreas coadministradas (centradas en la identificación de interesados directos, la creación de iniciativas de comunicación social, el desarrollo de procesos de negociación, la adopción consensuada de políticas, legislación y decisiones, que puedan crear un entorno favorable para la cogestión). Asimismo, la Recomendación pone el acento en el fomento de la participación de las comunidades locales en la adopción de decisiones relativas a la gestión 
de áreas protegidas, en la realización de actividades conjuntas de previsión y evaluación participativa, en la necesidad de apoyar la organización de los interesados directos y de fortalecer su capacidad de cogestión mediante cursos de capacitación básica y de perfeccionamiento para responsables de la gestión de los recursos naturales, visitas de intercambio nacional e internacional e iniciativas conjuntas de aprendizaje entre instituciones que se ocupan de áreas protegidas en los que se hayan emprendido actividades de cogestión"”l1.

Sin duda, de todos estos instrumentos jurídicos a que se refiere el autor, la propuesta de la UICN resulta ser la más avanzada en términos de gobernanza, trascendiendo lo que denominamos participación ciudadana, alcanzando a la implicación de las poblaciones locales en los proyectos de conservación, valorización y desarrollo de los espacios naturales protegidos. Este enfoque, por ahora, ha sido tímidamente acogido por la Ley 30/2014, de 3 de diciembre, de Parques Nacionales (LPN) que, aunque no se refiere expresamente a la Gobernanza, es una Ley más ambiciosa que la LPNB a la hora de concretar ese fomento a «la colaboración y participación activa de la sociedad en el logro de los objetivos de los parques nacionales» y promocionar «la implicación de los titulares de derechos privados en los parques nacionales, así como de la población residente en sus entornos» (art. 2), teniendo en cuenta que en la regulación anterior sólo se hacía referencia a la Administración y a los propietarios ${ }^{12}$. Esta comprensión nos recuerda a la cuarta tipología de gobernanza acuñada por la UICN, que, como se verá, implica a los residentes del lugar. La LPNB, en su exposición de motivos, se refiere, en este sentido a «implicar a la sociedad en sus actividades», «suponer un ejemplo de gestión más participativa y más abierta a la sociedad y de aplicación de los principios de colaboración, coordinación y cooperación», «integrar sectores y colectivos en las actividades de gestión, así como implicar y apoyar a la población local residente».

\footnotetext{
11 Bermejo Latre, J. L., "La participación del público en la protección de la biodiversidad", Monografias de la Revista Aragonesa de Administración Pública, XVI, Zaragoza, 2016, págs. 169-171.

12 Ley 5/2007, de 3 de abril, de la Red de Parques. Nacionales.
} 


\section{La gobernanza de áreas marinas en el ordenamiento jurídico español: el silencio del término por parte de la LPMM}

Desde fechas relativamente recientes viene empleándose el término "gobernanza" al tratar prácticamente cualquier sector de intervención pública, como sinónimo de manera de gobernar más acorde con los tiempos actuales.

El diccionario de la RAE incluye dos acepciones del término. En primer lugar, se define como acción y efecto de gobernarse, indicando que se trata de una acepción en desuso. Y, en segundo lugar, como arte o manera de gobernar que se propone como objetivo el logro de un desarrollo económico, social e institucional duradero, promoviendo un sano equilibrio entre el Estado, la sociedad civil y el mercado de la economía. Se hace, pues, hincapié en la habilidad o arte para gobernar, teniendo en cuenta a la sociedad civil como actora de la gobernanza.

Pues bien, se trata de esta última acepción a la que sin duda se refiere la doctrina que ha tratado de conceptualizar la gobernanza, que ve en este modelo de gobierno una forma de organizar la acción colectiva para el logro de objetivos comunes, en la que participan tanto actores públicos como actores privados. De este modo, se pretende dar cabida al modelo de gobierno que acoge las transformaciones del Estado en la actualidad, que afectan también a las clásicas instituciones del derecho público.

En el plano jurídico, que es el que nos ocupa, es cierto que ya son numerosas las normas que se refieren a la gobernanza. Debemos apuntar, sin embargo, que, a la luz de nuestro ordenamiento jurídico, el término se emplea con diferentes significados como se verá infra.

En sede de espacios protegidos la UICN reconoce cuatro grandes tipos de gobernanza de áreas protegidas, cualquiera de los cuales puede asociarse con cualquier objetivo de gestión y en principio con cualquier tipo de bien (propiedad privada o bienes públicos). En primer lugar, la Gobernanza por parte del gobierno, o gobernanza pública, que puede identificarse con la gobernanza pública y que se aplicaría al cumplimiento de funciones públicas, a la prestación de servicios públicos y a la protección de los bienes de dominio público. En segundo lugar, la Gobernanza compartida, que implicaría una gestión "colaborativa" Que implica información y consulta de los agentes implicados. Esta gobernanza puede además reforzar la participación e implicar una gestión colaborativa, asignando a grupos de varios agentes implicados la responsabilidad de desarrollar propuestas técnicas para la regulación y gestión del área protegida, que serán finalmente remitidas a la autoridad de toma de decisiones para su aprobación. Se trataría del enfoque acogido para las áreas privadas de conservación, tal y como han establecido algunas CCAA. Otra modalidad de gobernanza compartida sería la gestión "conjunta”, según la cual diversas instancias 
de poder territoriales forman parte de la instancia que toma las decisiones y se responsabiliza de la gestión. Es posible que las decisiones requieran consenso, lo cual implica un complejo desarrollo de la capacidad de negociación. En tercer lugar, se encontraría la Gobernanza privada, cuyo exponente en nuestro ordenamiento jurídico sería la custodia del territorio. Y, por último, la Gobernanza por parte de pueblos indígenas y comunidades locales, no contemplada en el ámbito de los espacios naturales en el ordenamiento básico, sino en relación con los montes y que responde al modelo de gestión propio de los bienes comunales como categoría de bienes públicos, aunque también, salvando las distancias, por tratarse en todo caso de un bien de dominio público - a diferencia de lo que sucede en relación con los espacios naturales, con el reconocimiento del derecho consuetudinario en materia de aguas. La UICN define este tipo de gobernanza aplicada al medio natural como áreas protegidas donde la autoridad administrativa y la responsabilidad recaen en los pueblos indígenas y/o comunidades locales bajo diversas formas de instituciones y normas, consuetudinarias o legales, formales o informales. Éstas pueden resultar bastante complejas. Por ejemplo, según la UICN los recursos terrestres y/o marinos pueden ser propiedad y ser gestionados por los pueblos, enfoque que encuentra problemas de encaje en nuestro ordenamiento jurídico, por la propia naturaleza demanial del dominio público marítimo terrestre.

Descendiendo al plano normativo, puede afirmarse que todavía son escasas, aunque cada vez más frecuentes, las normas que emplean el término gobernanza, aunque para referirse a realidades diversas. Además, el término es recurrente en las Exposiciones de motivos y títulos al diseñarse la estructura de las normas, omitiéndose en todos los casos un deseable concepto jurídico de gobernanza.

Así, la Ley 14/2011, de 1 de junio, de la Ciencia, la Tecnología y la Innovación emplea el término en el título I sobre Gobernanza del Sistema Español de Ciencia, Tecnología e Innovación, modelo que comprende estrategias -Estrategia Española de Ciencia y Tecnología y Estrategia Española de Innovación (arts. 6 y 7),- planes -Plan Estatal de Investigación Científica y Técnica y Plan Estatal de Innovación (arts. 42 y 43)- y órganos de gobernanza, como la Comisión Delegada del Gobierno para Política Científica, Tecnológica y de Innovación (art. 41). Se trata, en este caso de una gobernanza pública en la que a lo sumo existe participación en los procedimientos de elaboración de las estrategias y los planes, participación que, sin embargo, se echa en falta en el plano organizativo, dada la composición íntegramente pública del órgano de gobernanza creado.

Por su parte, el Real Decreto-ley 4/2015, de 22 de marzo, para la reforma urgente del Sistema de Formación Profesional para el Empleo en el ámbito laboral, se refiere en su Exposición de motivos al Sistema de Gobernanza (pública) de la 
formación profesional, como sinónimo de ordenación pública de un servicio público educativo.

El Real Decreto 769/2017, de 28 de julio, por el que se desarrolla la estructura orgánica básica del Ministerio de Hacienda y Función Pública y se modifica el Real Decreto 424/2016, de 11 de noviembre, por el que se establece la estructura orgánica básica de los departamentos ministeriales, crea la Dirección General de Gobernanza Pública como órgano administrativo dependiente del Ministerio, en cuya composición no se atisba ninguna presencia extraña a lo público.

La Ley 45/2007, de 13 de diciembre, para el desarrollo sostenible del medio rural también en su parte expositiva advierte que la aplicación de esta Ley requiere un elevado grado de gobernanza, para lo cual se establecen instrumentos de programación y colaboración entre Administraciones, principalmente un Programa de Desarrollo Rural Sostenible plurianual, y se promueve e incentiva la participación del sector privado en el proceso de desarrollo rural sostenible. Se trata, sin duda, de un paso adelante en la gobernanza, que en este caso comprende la colaboración entre Administraciones y la participación del sector privado en la consecución del desarrollo sostenible del medio rural.

Quizá las normas más trasversales que aluden expresamente a la gobernanza sean las leyes autonómicas sobre transparencia que han proliferado en los últimos años. Puede citarse, en primer término, la Ley 12/2014, de 16 de diciembre, de Transparencia y Participación Ciudadana de la Comunidad Autónoma de la Región de Murcia, cuyo art. 3 incluye, entre los principios generales que inspiran esta ley el principio de gobernanza, enfocado a garantizar la interacción de las distintas instancias públicas, los entornos cívicos y económicos, y la ciudadanía, en el proceso de toma de decisiones. Se adopta, pues, un avanzado concepto de gobernanza que va más allá de la participación en los procedimientos o en la composición de órganos sin competencias decisoras, para comprender una verdadera participación en la toma de decisiones en asuntos públicos. No obstante, este principio debe ser concretado por la normativa sectorial, en la medida en que no deja de ser una declaración de intenciones en el plano teórico, difícilmente invocable para exigir una participación real en asuntos concretos. En similar sentido, también son dignas de mención, por contener el término gobernanza en su texto, la Ley 4/2016, de 15 de diciembre, de Transparencia y Buen Gobierno de Castilla-La Mancha o la Ley 5/2017, de 1 de junio, de Integridad y Ética Públicas de Aragón, que en su exposición de motivos advierte que la consolidación de la democracia requiere que el conjunto del modelo institucional y social asuma como elemento estructural la transparencia, la participación, la integridad y la ética pública, contribuyendo de este modo a una mejor gobernanza, a 
mejores prácticas regulatorias, a un mejor servicio a los intereses generales y a las demandas sociales

Muy interesante, y ya de parte de la normativa sectorial, resulta la Ley 10/2014, de 27 de noviembre, de Aguas y Ríos de Aragón, que habla de gobernanza del agua para referirse al modelo que se deriva de la Directiva 2000/60/CE, por la que se establece un marco comunitario de actuación en el ámbito de la política de aguas, en relación a la participación pública en la toma de decisiones en la organización del agua y al acceso de todos los interesados a la información sobre el medio hídrico, otorgando a esta información la consideración de ambiental a los efectos establecidos en la normativa comunitaria.

En sede de áreas marinas protegidas, aunque pueda sorprender, ni la DMEM ni la LPMM emplean el concepto de gobernanza. No obstante, sí podemos identificar elementos o técnicas jurídicas que incorporan algunos de los modelos de gobernanza referidos supra y que ha categorizado la UICN.

Así, un elemento fundamental de la gobernanza marina que aporta la DMEM es la participación del público, al establecer la obligación de los Estados miembros de velar por que las partes interesadas puedan participar en la aplicación de esta Directiva, además de la obligación de poner a disposición del público resúmenes sobre los elementos del Plan de Acción para la elaboración de las estrategias marinas al objeto de que pueda presentar sus observaciones. No se concreta el alcance de esta participación, que podría llegar, como hemos tratado a lo largo del presente estudio, al reconocimiento de la iniciativa privada para la iniciación del procedimiento de declaración de las AMPS o la positivación de una nueva figura de AMP de carácter privado o, incluso, local.

Otro elemento significativo, y que constituye un presupuesto para la participación, es el deber de facilitar acceso a la información de acuerdo a lo previsto en la Directiva 2003/4/CE, del Parlamento Europeo y del Consejo, relativa al acceso del público a la información medio ambiental y su transposición al Derecho español mediante la Ley 27/2006.

Cabe concluir afirmando la necesidad de avanzar en el concepto jurídico de gobernanza y, en relación con las áreas marinas, contemplar dicho modelo, reforzando la presencia de instrumentos propios de esta modalidad de gobierno de los bienes del demanio natural marítimo-terrestre. 


\section{MODELOS DE GOBERNANZA APLICABLES AL MEDIO MARINO}

Además de la GIZC, y de los eventuales espacios marinos de interés particular, aún no contemplados por la normativa básica estatal, nuestro ordenamiento jurídico sí da cabida a dos instrumentos que pueden ser tenidos como auténticos modelos para la gobernanza de AMPS: los convenios de colaboración para la gestión integral del litoral y la custodia del territorio aplicada al medio marino.

\section{Gestión integrada de zonas costeras como modelo de gobernanza: planificación integral y participada}

Con el objeto de abordar muchos de los problemas que se plantean en las zonas costeras, diferentes organismos nacionales e internacionales han desarrollado específicos modelos de gestión ${ }^{13}$. Por su parte, la UE ha venido desarrollando en el marco de la política ambiental comunitaria, desde mediados de los setenta, diversas iniciativas con el fin de promover la gestión sostenible e integral de las zonas costeras de Europa ${ }^{14}$.

La gestión integrada de zonas costeras y gestión integrada del litoral, puede quedar definida como un modelo de gestión en el ámbito público que tiene en cuenta los principios de colaboración, cooperación y gobernanza y se compromete con la participación ciudadana (Recomendación del Parlamento Europeo y del Consejo, de 30 de mayo de 2002, sobre la aplicación de la gestión integrada de las zonas costeras en Europa $)^{15}$. Lo que se pretende es poner en práctica los principios de integración y subsidiariedad para aumentar la eficacia de los instrumentos existentes, así como

13 Resolución (73)29 del Consejo de Europa sobre protección del litoral; Recomendación del Consejo de la OCDE sobre principios para la ordenación costera, C(76) 161, adoptada en 12 de octubre de 1976; Carta Europea del Litoral, aprobada en 1981 por la Asamblea plenaria de la Conferencia de Regiones Periféricas y Marítimas de la Comunidad Europea; Resolución de los Ministros de Planificación sobre las áreas de costa del Consejo de Europa, 1983; Recomendación del Consejo de la OCDE de 1992, sobre gestión integrada de las zonas costeras; Programa 21 de la Conferencia de Naciones Unidas sobre Medio Ambiente y Desarrollo (Capítulo 170, sección 17.3 y 17.5).

14 Declaración del Consejo de Ministros sobre el programa de acción medioambiental de la Comunidad Europea (1973-J977); Comunicación COM(86)571: la ordenación integrada de las zonas costeras: su función en la política comunitaria de medio ambiente; Resolución del Consejo de 25 de febrero de 1992, sobre la gestión integrada de las zonas costeras; Resolución del Consejo y de los representantes de los Estados miembros, reunidos conjuntamente con el Consejo, sobre el programa comunitaria de política y actuaciones en materia de medio ambiente y de desarrollo sostenible $\left(5^{\circ}\right.$ Programa de Acción de la CE, 93/C 138/01)47; Comunicación de la Comisión "Europa 2000 +" (Comunicación de la Comisión COM/94/354); Resolución del Consejo, de 6 de mayo de 1994, relativa a una estrategia comunitaria de gestión integrada de la zona costera; Comunicación de la Comisión al Consejo y al Parlamento Europeo sobre gestión integrada de las zonas costeras, $\mathrm{COM}(95) 51 \mathrm{~J}$ final (Bruselas, 31.10.95).

15 Puede consultarse el Informe de España en cumplimiento de los requerimientos del capítulo VI de la Recomendación del Parlamento Europeo y del Consejo de 30 de Mayo de 2002 sobre la aplicación de 
la coordinación recíproca entre los campos de actividad y los diferentes niveles de competencia territorial ${ }^{16}$.

La Estrategia europea para la gestión integrada de las zonas costeras la describe como "un proceso dinámico, continuo e iterativo destinado a promover la gestión sostenible de las zonas costeras". Un proceso que tiene por finalidad: "conseguir equilibrar a largo plazo, dentro de los límites impuestos por la dinámica natural y la capacidad de carga de la zona, los beneficios del desarrollo económico y de los usos de la zona costera por los seres humanos, de la protección, preservación y restauración de las zonas costeras, de la reducción de las pérdidas en términos de vidas humanas y de daños a las cosas y del acceso y disfrute públicos de la costa"17.

En el proceso de ordenación integral del litoral resulta imprescindible la toma de conciencia de las cuestiones de interés común, el diálogo e intercambio de opiniones entre las partes interesadas y afectadas, así como el favorecimiento de la cooperación entre las partes implicadas para lograr una acción coordinada y una gestión integrada. La GIZC permite diseñar un modelo para cada lugar que depende del contexto histórico, cultural y tradicional y de las condiciones naturales y los problemas físicos de la zona.

Tanto la doctrina como diversos organismos vienen proponiendo desde hace décadas diversos modelos de GIZC a partir del análisis geográfico y de la ordenación del territorio, analizando las peculiaridades geográficas, económicas y administrativas del litoral, para ofrecer finalmente diversas recomendaciones y orientaciones metodológicas para la ordenación y planificación del litoral como espacio "polidisputado".

la gestión integrada de las zonas costeras en Europa (http://www.upv.es/contenidos/CAMUNISO/info/ U0652473.pdf).

16 Ley Federal de los Estados Unidos sobre "Gestión de las Zonas Costeras" de 1972; Ley francesa 211986, de 3 de enero, relativa a la ordenación, protección y revalorización del litoral (la llamada «Loi Litoral»). Cfr. MORENO CANOVES, A., Régimen jurídico del litoral, Tecnos, Madrid 1990, pp. 83 a 104; CALERO RODRIGUEZ. op. cit. pp. 59-63. Sobre la experiencia francesa, vid. GHEZALI, M.: Gestion Intégrée des Zones Cotieres. L'approche Statutaire de la Zone Cote-D’Opale, Université du Litoral, 2000; Vid. asimismo RUIZ, J., Derecho Internacional del Medio Ambiente, cil. pp. 131-257; URENA ÁLVAREZ, M.R.: La protección del medio marino en España, Universidad de Valladolid, Valladolid 1986; y MARTÍN MATEO, R., "Planificación ambiental oceánica", en Revista de Cestúin Ambiental, enero de 1999, pp. 3-9.

17 La Estrategia puede consultarse en http://ec.europa.eu/environment/iczm/pdf/exsum_es.pdf 
A. La gestión integrada de zonas costeras (GIZC) en España. La conveniente integración de los espacios naturales marinos en su ámbito territorial

En España, la GIZG se encuentra con una adicional dificultad derivada de la compleja distribución de competencias, que complica, como recuerda MENENDEZ REXACH, que es posible que "no pueda avanzarse mucho por la vía de la gestión integral mediante propuestas de simplificación administrativa consistentes en la concentración de las competencias en algunos de los tres niveles territoriales. Este objetivo puede alcanzarse más bien mediante la correcta articulación del ejercicio de las competencias que respectivamente corresponden a cada una de esas esferas territoriales, para lo que deberán utilizarse las técnicas previstas en la normativa vigente (convenios, procedimientos conjuntos, órganos comunes, etc.), que son más que suficientes si se tiene voluntad de utilizarlas. La gestión integral de la costa no implica una opción organizativa específica, sino que debe ser cada vez más el resultado de la cooperación y coordinación entre las instituciones interesadas y obligadas a intervenir en el ejercicio de sus competencias respectivas" ${ }^{18}$.

Las Comunidades Autónomas, desde hace décadas, han liderado importantes iniciativas de carácter normativo que adoptan la perspectiva de la gestión integrada del litoral, como la ya derogada Ley 3/1987, de 23 de abril, de "Protección y Armonización de Usos del Mar Menor", de la Comunidad Autónoma de Murcia, las Directrices Regionales del Litoral de Andalucía, aprobadas por Decreto 118/1990, de 17 de abril, el Plan de Mejora Ambiental del Litoral de Andalucía (1995-2000), las Directrices Subregionales de Ordenación del Territorio para la Franja Costera del Principado de Asturias", aprobadas por Decreto 107/1993, de 16 de diciembre, los Planes de Ordenación del Litoral de la Comunidad Autónoma de Baleares, aprobados por Decreto 72/1994, de 26 de mayo), y la Ley 4/1998 de "Protección del Cap de Creus" de la Comunidad Autónoma de Cataluña, entre otras.

En la Región de Murcia, aunque se encuentra paralizada por la oposición de diversos sectores económicos, se hizo público hace unos meses el Avance de la Estrategia de Gestión Integrada de Zonas Costeras del Sistema Socio-Ecológico del Mar Menor y su Entorno (SSEMM) ${ }^{19}$ La estrategia GIZC SSEMM pretende afrontar los principales problemas y conflictos que afectan al SSEMM formulando orientaciones para una política pública de GIZC en un marco de gobernanza con fines destinados a la sostenibilidad del bienestar humano y la conservación ecológica, centrando la atención en la gestión de los bienes públicos y comunes del SSEMM, fortaleciendo la capacidad institucional y favoreciendo la coordinación y cooperación entre diferentes escalas territoriales de gestión pública, involucrando a todos los agentes sociales e institucionales implicados o interesados en la administración del SSEMM, promoviendo la conciencia pública sobre su valor con objeto de incidir en el compor-

\footnotetext{
18 Ibidem, p. 47 y ss.

19 http://sitmurcia.carm.es/documents/13454/4801272/Resumen+del+Avance/
} 
tamiento social y facilitando el diálogo entre diferentes disciplinas del conocimiento orientándolas, además, hacia una mejor integración con los procesos de toma de decisiones en el ámbito público y privado. Con este modelo participativo de gestión se persigue aportar líneas estratégicas prioritarias para el desarrollo de los distintos sectores de actividad en el Mar Menor (turismo, agricultura, actividades náuticas y deportivas, urbanismo, minería, pesca.... $)^{20}$.

Se observan, pues, tímidos avances en la implantación de la GIZC, en la que los objetivos perseguidos por la LPNB y LPMM deberían integrarse.

B. Posible esquema normativo para la implantación del modelo de gestión integrada de las zonas costeras propuesto por SANZ LARRUGA

Siguiendo la Ley-modelo sobre la protección de las zonas costeras del Consejo de Europa, de 1997 (elaborada bajo la dirección de Michel PRIEUR), SANZ LARRUGA propone una serie de principios y criterios que, a su juicio, deberían orientar las futuras iniciativas de gestión integrada del litoral en España y que por su relevante interés transcribimos a continuación:

$1^{\circ}$. Convenir en una definición de "gestión integrada"; la que ofrece la "Leymodelo" es esta: "la gestión sostenible de las zonas costeras tomando en consideración el desarrollo económico unido a la presencia del mar y su plena salvaguardia, para las generaciones presentes y futuras, los equilibrios biológicos y ecológicos frágiles de la zona intermareal".

$2^{\circ}$. Formular unos principios orientadores de tal proceso, distinguiendo los que proceden directamente de la política ambiental -desarrollo sostenible, prevención, precaución, restauración, quien contaminador-pagador, e información y participación Prioridad de las actividades dependientes del litoral.

- Internalización de los costes de protección.

- El que contamina paga.

3․ Previsión en el plan o planes autonómicos (Directrices y Planes de ordenación del litoral) de la autoridad que ha de dirigir el proceso y la participación de actores y entidades sociales en los organismos de gestión, asi como el asesoramiento de un Comité científico compuesto por expertos pluridisciplinares en la materia maritima y costera.

20 Anuncio de la Dirección General de Ordenación del Territorio, Arquitectura y Vivienda de la Consejería de Fomento e Infraestructuras, por la que se somete a información pública el avance de estrategia de gestión integrada de zonas costeras del sistema socio-económico del Mar Menor (BORM núm. 98, de 29/04/2017). 
4․ Distribución de las competencias entre los diferentes poderes públicos, en particular, entre las CCAA y los Entes locales, y los mecanismos de colaboración y coordinación.

5․ Previsión de instrumentos destinados a proporcionar un mejor conocimiento de las zonas costeras: inventarios, cartografía ecológica y jurídica, red de centros de investigación, contabilidad del patrimonio natural costero, etc.

$6^{\circ}$. Creación de instrumentos financieros y de fomento de las zonas costeras: fondos públicos, impuestos ecológicos, acuerdos voluntarios, etc.

$7^{\circ}$. Exigencia de aplicación generalizada de la evaluación de impacto ambiental sobre todas las actividades, planes y programas, tanto de naturaleza pública como privada, que puedan afectar a los ecosistemas litorales.

8․ Establecimiento de medidas de protección sobre ciertas actividades (pesca marina y submarina), sobre los ecosistemas costeros más frágiles como las zonas húmedas, dunas, reservas marinas, etc.

9․ Previsión de medidas específicas contra la erosión costera, la contaminación (gestión de los vertidos) y prevención de catástrofes naturales.

10 . Determinación de los mecanismos de información y participación ciudadana.

Por lo que se refiere a la compleja cuestión de la coordinación de competencias de las Administraciones que concurren sobre el litoral y sin forzar el vigente sistema de reparto constitucional de competencias, el proceso de gestión integrada podría construirse bajo las siguientes directrices. En primer término, a la Administración del Estado correspondería la aprobación de la legislación básica y la aportación de los recursos financieros necesarios para abordarla. En segundo lugar, a las CCAA el desarrollo de la legislación del Estado -y en su caso, las normas adicionales de protección- y la planificación territorial del litoral. A los Municipios costeros, la ejecución de los planes, programas y medidas que sean oportunas.

En definitiva, no se requieren grandes reformas normativas para introducir en España el modelo de gestión integrada y sostenible de las zonas costeras sino más bien, como estima el autor, "la imprescindible voluntad política en su aplicación". 


\section{Los convenios de colaboración en el ámbito de gestión de las áreas marinas}

A pesar del creciente empleo del convenio de colaboración y del hecho de que a través de este instrumento se canalicen importantes cantidades de recursos públicos, esta figura carecía de una regulación sistemática en nuestro país, al menos, en el ámbito de la legislación del Estado hasta fechas recientes ${ }^{21}$. El insuficiente marco regulatorio de los convenios ha dado pie a prácticas "que soslayan la aplicación de la legislación contractual, resintiéndose, por tanto, la gestión de los fondos públicos que discurre por cauces jurídicamente inseguros, y la aplicación de los principios de legalidad, eficiencia y economía"22. Una conducta generalizada que, como señala Fuertes López, ha dado lugar a "una gran vía de agua en la legislación española hecha a golpe de convenio que han podido hundir todo el barco de previsiones legislativas que tratan de garantizar una actuación contractual pública, que garantiza la no discriminación y favorece la competencia empresarial"'23. Misma conducta que ha hecho necesaria, en no pocas ocasiones, la intervención de los Tribunales para la declaración de nulidad de muchos de estos convenios.

En realidad, el problema radica en que la normativa reguladora de los convenios se ha encontrado tradicionalmente dispersa en una multiplicidad de normas poco claras. Muchas de ellas destinadas a regular aspectos parciales o modalidades concretas, y solo algunas, las menos, a la regulación de elementos comunes ${ }^{24}$. Un foco inagotable de dudas sobre la correcta legislación aplicable que ha afectado, tanto a los gestores públicos y los órganos de control, como a los terceros con los que se formalizan los convenios.

Al fin la LRJSP desarrolla en el Capítulo vi del Título preliminar (arts. 47 a 53 y disp.. adic. $8^{\mathrm{a}}$ ), un completo régimen jurídico básico de los convenios aplicable a todas las Administraciones públicas ex art. 149.1.18 ${ }^{\mathrm{a}} \mathrm{CE}^{25}$. La importancia de cuanto

21 En este sentido, el Informe de la Secretaría de Estado de Cooperación Territorial sobre los Convenios de colaboración Estado-CCAA suscritos durante 2009, señala que, el número de convenios suscritos en el periodo 1999-2009, ascendió a un total de 10.251, elevándose la aportación estatal por esta vía a 32.527,40 millones de euros.

22 Dictamen del TC núm. 878, de 30 de noviembre de 2010, p. 7.

23 Fuertes López, M., "Los convenios y los consorcios en la Ley del Sector Público", conferencia impartida en el Seminari de Dret Local: les lleis 39 i 40 de 2015, de Procediment Administratiu i Règim Furídic del Sector Públic, Federación de Municipios de Cataluña, Barcelona, 20 de noviembre de 2015, p. 16.

24 Como señala el TC, "estas normas abordan aspectos parciales o modalidades concretas, de las cuales sólo algunas, pueden considerarse comunes a los distintos tipos de convenios, mientras que otras únicamente conciernen a algunos de ellos”. Dictamen del TG núm. 878, de 30 de noviembre de 2010, cit., p. 15.

25 Se recogen las recomendaciones contempladas tanto en el Dictamen del TG núm. 878, de 30 de noviembre de 2010, como en el Informe CORA, de 21 de junio de 2013, constituyen el germen del marco jurídico básico, sustantivo y de procedimiento, de los convenios que se recoge en la LRJSP y con el 
se expone a continuación queda patente a la luz de la Disposición adicional 8 a , pues al margen del plazo de tres años previsto para la adaptación de los convenios preexistentes, contempla la aplicación automática de las nuevas reglas sobre vigencia a todos los convenios que no tuvieran un plazo determinado o que, aun teniéndolo, tuvieran establecida una prórroga tácita por tiempo indefinido en el momento de la entrada en vigor de la Ley ${ }^{26}$.

Por lo que al presente estudio interesa, puede afirmarse existencia de convenios de colaboración entre Administraciones Públicas a fin de lograr objetivos concretos, incluidos la conservación ambiental de la costa, aunque en realidad estos no han tenido apenas aplicación práctica.Sirvan de ejemplo los Convenios firmados para la gestión integral del litoral, - por citar algunos, el Convenio de colaboración entre el Ministerio de Medio Ambiente, la Consejería de Política Territorial, Obras Públicas y Transportes, la Consejería de Medio Ambiente y Desarrollo Sostenible y la Consejería de Pesca y Asuntos Marítimos de la Junta de Galicia, para la gestión integral y sostenible del litoral ${ }^{27}$; el Convenio de colaboración entre el Ministerio de Medio Ambiente y el Gobierno de Canarias para la gestión integral y sostenible del litoral ${ }^{28}$ y, en fin, el Convenio de Colaboración entre el Ministerio de Medio Ambiente y el Principado de Asturias en la gestión integral del litoral asturiano ${ }^{29}$. Estos convenios se suscribieron sujetos a un plazo no determinado de duración máxima, aspecto que desde la entrada en vigor de la LRJSP debe corregirse, quedando afectados de lleno por la obligación de acomodarse al contenido de la nueva Ley.

Estos convenios de colaboración se suscriben con el objeto de establecer un marco estable de coordinación y colaboración entre las Administraciones implicadas, dentro del marco de sus competencias. Se trata este de uno de los requisitos fundamentales para la validez de los convenios a la luz del nuevo régimen introdu-

que se pretende dar respuesta a las dudas y prácticas irregulares que han caracterizado el uso común de los convenios de colaboración.

26 En estos casos, de acuerdo con la Disposición adicional $8^{\mathrm{a}}$, el plazo de vigencia de los convenios será de cuatro años a contar desde el pasado día 2 de octubre de 2016.

27 Resolución de 23 de marzo de 2007, de la Dirección General de Costas, por la que se publica el Convenio de colaboración entre el Ministerio de Medio Ambiente, la Consejería de Política Territorial, Obras Públicas y Transportes, la Consejería de Medio Ambiente y Desarrollo Sostenible y la Consejería de Pesca y Asuntos Marítimos de la Junta de Galicia, para la gestión integral y sostenible del litoral, («BOE» núm. 92, de 17 de abril de 2007).

28 Resolución de 23 de marzo de 2007, de la Dirección General de Costas, por la que se publica el Convenio de colaboración entre el Ministerio de Medio Ambiente y el Gobierno de Canarias para la gestión integral y sostenible del litoral, («BOE» núm. 94, de 19 de abril de 2007).

29 RESOLUCIÓN de 24 de junio de 2004, de la Dirección General de Costas, por la que se ordena la publicación del Convenio de Colaboración entre el Ministerio de Medio Ambiente y el Principado de Asturias en la gestión integral del litoral asturiano («BOE» núm. 184, de 31 de julio de 2004). 
cido por la LRJSP. En los casos referidos, las competencias de las Administraciones implicadas suelen encuadrarse en las siguientes: por parte de la AGE, el Ministerio de Medio Ambiente tiene la competencia exclusiva en materia de determinación, protección, utilización y policía del dominio público marítimo-terrestre, recogida en la Ley 22/1988, de Costas, a cuyo amparo desarrolla una política de recuperación de las áreas costeras y defensa del dominio público marítimo-terrestre, con el objetivo de mejorar su calidad ambiental y garantizar el uso público de los espacios cercanos al mar. Asimismo, ejerce competencias relativas a la evaluación de impacto ambiental sobre el dominio público marítimo-terrestre de una serie de infraestructuras de interés general, que en algunos casos pueden incidir en la ordenación de la franja litoral. Por su parte, las Administraciones autonómicas ostentan la competencia en materia de urbanismo, ordenación del territorio y del litoral y tutela de la zona de servidumbre de protección de costas; sin olvidar las competencias en materia de ordenación pesquera y medio ambiente y conservación de la naturaleza. Por tanto, nada obsta acomodar la figura de estos convenios a los títulos competenciales concurrentes en materia de áreas marinas.

Ambas Administraciones, Estado y CGAA, a través de este instrumento se comprometen a prestarse apoyo técnico, así como a coordinarse y cooperar de forma activa en el desarrollo de las distintas actuaciones a llevar a cabo. De conformidad con el nuevo régimen previsto, debe existir una determinación expresa, clara y precisa, no solo de las actuaciones a desarrollar por cada una de las AAPP implicadas, sino de las consecuencias derivadas de su incumplimiento.

En muchos casos llega a quedar prevista la firma de convenios específicos a suscribir con Ayuntamientos y otras partes implicadas, actuaciones complejas para la transformación y adecuación, por ejemplo, del dominio público marítimo-terrestre y sus zonas de servidumbre, a los objetivos de protección y mejora del litoral, preservando sus valores ambientales, así como el uso público del litoral, realizando una ordenación y gestión integrada del litoral que asegure la sostenibilidad ambiental del mismo.

Para garantizar el control y seguimiento han quedado tradicionalmente previstas las Comisiones Mixtas de Seguimiento, formadas por cuatro representantes de cada una de las Administraciones intervinientes. Este órgano debe adaptarse a las nuevas previsiones establecidas tras la reforma de la LRJSP, pero en todo caso permitirá la cooperación y colaboración en el análisis y en la toma de decisiones en relación a cualquier aspecto técnico, jurídico y/o ambiental que concierna al litoral, todo ello en el marco de los procedimientos legalmente establecidos y con pleno respeto a las competencias que cada una de las Administraciones intervinientes despliega sobre la costa. 
El consenso que implican estos convenios posibilita una planificación a la vez integral e integradora de la gestión marina. Desde el recíproco conocimiento y respeto de todas las posturas afectadas, teniendo en cuenta que más que una alternativa, el consenso como fuente de la planificación es una exigencia que plantea la forma de organización territorial que eligió el constituyente para el Estado español, y ello sin perjuicio de las competencias que el bloque constitucional reserva a cada Administración Pública, de las que no pueden hacer dejación.

\section{La custodia del territorio aplicada al medio marino. Su inacabado diseño en la LPNB}

A pesar de no haber positivado las áreas de protección privada (APP) como categoría de espacio natural protegido, la LPNB sí introduce en el ordenamiento jurídico estatal la custodia del territorio como herramienta de conservación, aunque sin conferirle una regulación completa.

La custodia del territorio se define como "conjunto de estrategias o técnicas jurídicas que implican a los propietarios y usuarios del territorio en la conservación y uso de los valores y los recursos naturales, culturales y paisajísticos" (art. 3). En efecto, este instrumento consiste en un conjunto de estrategias y técnicas jurídicas que pretenden favorecer y hacer posible la responsabilidad de los propietarios y usuarios del territorio en la conservación de sus valores naturales, culturales y paisajísticos, así como en el uso adecuado de sus recursos. En consonancia con lo anterior, el art. 4 de la LPNB dispone que en "la planificación y gestión de los espacios naturales protegidos y las especies amenazadas se fomentarán los acuerdos voluntarios con propietarios y usuarios de los recursos naturales". Se reconoce, pues, la aplicación de la custodia del territorio como herramienta de manejo en manos privadas tanto dentro como fuera de los límites de los espacios naturales protegidos, sean Red Natura 2000 o no.

Las entidades de custodia del territorio se definen, por su parte, como "organización pública o privada, sin ánimo de lucro, que lleva a cabo iniciativas que incluyan la realización de acuerdos de custodia del territorio para la conservación del patrimonio natural y la biodiversidad".

En tercer término, como una clara obligación de fomento, el art. 72 de esta misma Ley, en su redacción original, reguló la promoción de la custodia del territorio estableciendo una obligación general, dirigida a todas las AAPP de fomento de la custodia del territorio mediante acuerdos entre entidades de custodia del territorio y propietarios de fincas privadas o públicas que tengan por objeto principal la conservación del patrimonio naturaly la biodiversidad (art. 72.1. LPNB). En el caso de que la AGE sea titular de los terrenos situados en los espacios naturales, se establece la posibilidad de llevar a cabo "el desarrollo de los acuerdos de cesión de su gestión, total o parcial de los mismos a entidades de custodia del territorio. Estos acuerdos para la cesión de la gestión, se establecerán por escrito, en forma de 
convenio administrativo plurianual que preverá el sistema de financiación para su desarrollo, bien mediante aportaciones económicas, edificaciones, equipamientos, maquinaria, vehículos o cualquier otro bien o servicio, así como las directrices minimas de gestión, fijadas en un precedente plan de gestión" (art. 72.2 LPNB).

Si esta fue la escueta regulación que la LPNB dispensó a la custodia del territorio, posteriormente, el art. 36.3 de la Ley 25/2009, de 22 de diciembre, de modificación de diversas leyes para su adaptación a la Ley sobre el libre acceso a las actividades de servicios y su ejercicio, introdujo un nuevo inciso al apartado 2 del art. 72 de la LPNB, añadiendo que "la selección de estas entidades se llevará a cabo de acuerdo con los principios de publicidad, objetividad, imparcialidad, transparencia y concurrencia competitiva. Los acuerdos para la cesión de la gestión tendrán una duración limitada de acuerdo con sus características, y no darán lugar a renovación automática, no conllevando, una vez extinguida, ningún tipo de ventaja para el anterior cesionario ni para personas vinculadas a él".

Además de la genérica función de promoción de las iniciativas privadas de conservación de la naturaleza, los arts. 73 y 74 de la LPNB van más allá, apoyando expresamente los "incentivos a las externalidades positivas" derivados de la gestión privada de espacios naturales y creando el Fondo para el Patrimonio Natural y la Biodiversidad. En este caso se establece que serán las CCAA las que regulen los mecanismos y las condiciones para incentivar las externalidades positivas de terrenos que se hallen ubicados en espacios declarados protegidos o en los cuales existan acuerdos de custodia del territorio debidamente formalizados por sus propietarios ante entidades de custodia. Para ello se tendrán en cuenta, entre otros, los siguientes servicios prestados por los ecosistemas: a) La conservación, restauración y mejora del patrimonio natural, de la biodiversidad, geodiversidady del paisaje en función de las medidas específicamente adoptadas para tal fin, con especial atención a hábitats y especies amenazados. b) La fijación de dióxido de carbono como medida de contribución a la mitigación del cambio climático. c) La conservación de los suelos y del régimen hidrológico como medida de lucha contra la desertificación, en función del grado en que la cubierta vegetal y las prácticas productivas contribuyan a reducir la pérdida o degradación del suelo y de los recursos hídricos superficiales y subterráneos. d) La recarga de acuíferos y la prevención de riesgos geológicos (art. 73 LPNB) ${ }^{30}$.

30 Asimismo, se crea, como hemos advertido, el Fondo para el Patrimonio Natural y la Biodiversidad, con objeto de poner en práctica aquellas medidas destinadas a apoyar la consecución de los objetivos de esta Ley, así como la gestión forestal sostenible, la prevención estratégica de incendios forestales y la protección de espacios forestales y naturales en cuya financiación participe la AGE. Dicho fondo podrá financiar acciones de naturaleza plurianual y actuará como instrumento de cofinanciación destinado a asegurar la cohesión territorial. El fondo se dotará con las partidas asignadas en los Presupuestos Generales del Estado, incluidas las dotaciones que sean objeto de cofinanciación por aquellos instrumentos financieros comunitarios destinados a los mismos fines y con otras fuentes de financiación que puedan establecerse en el futuro (art. 74.1. LPNB). Entre los objetivos del fondo, se establece expresamente el de Financiar acciones específicas relacionadas con la custodia del territorio (art. 74.2.m). La gestión de las subvenciones que se otorguen con 
Por su parte, el Real Decreto 1274/2011, de 16 de septiembre, por el que se aprueba el Plan estratégico del patrimonio natural y de la biodiversidad (2011-2017), en aplicación de la LPNB, que representa la aplicación del Plan Estratégico del Convenio sobre Diversidad Biológica en España, también insistió en la necesidad de fomentar y reconocer el papel que juegan los agentes sociales y privados en la gestión directa de la biodiversidad. Por ello, se considera imprescindible ampliar los esfuerzos en la promoción de la gestión concertada a cargo de entidades de custodia y otras entidades de gestión, además de las instituciones públicas implicadas, para la conservación del patrimonio natural y la biodiversidad. Esto permitiría explorar, por ejemplo, vías para el pago por algunos de los servicios de los ecosistemas. Los espacios de la Red Natura 2000 o las reservas de la biosfera son lugares idóneos para avanzar en la aplicación de este enfoque. El referido Plan contempla como objetivos concretos la creación de un registro estatal de entidades de custodia, determinar las tipologías y condiciones de las entidades de custodia, así como de acuerdos de custodia y formas de gestión concertada de la biodiversidad. Pueden destacarse los siguientes objetivos concretos en relación con la custodia de territorio: promover acuerdos de custodia del territorio en terrenos de titularidad estatal en el marco del art. 72 de la LPNB, desarrollar acciones para la promoción de la custodia del territorio, desarrollar criterios de buenas prácticas para la custodia del territorio, modelos de acuerdos de custodia y modelos de seguimiento de la custodia del territorio y fomentar la Responsabilidad Social de la Empresa a través de iniciativas de custodia del territorio y gestión concertada de espacios naturales. Queda claro, pues, que resulta prioritario desarrollar la LPNB, concretamente el Gobierno debe elaborar el Registro de entidades y definir los acuerdos.

Por otra parte, la planificación sectorial programada también contempla la custodia del territorio como estrategia útil para compatibilizar la conservación y el desarrollo de algunos sectores económicos como el turismo. Así, el Real Decreto 416/2014, de 6 de junio, por el que se aprueba el Plan sectorial de turismo de naturaleza y biodiversidad 2014-2020, establece, que el impulso del modelo de turismo de la naturaleza, y sus garantías de éxito, deben ir acompañadas de la consolidación de los mecanismos de gobernanza en este ámbito, reforzando el marco de colaboración y coordinación entre las distintas administraciones públicas y entre el sector público,

cargo al Fondo corresponde a las CCAA, con las que previamente se habrán establecido mediante convenio las medidas a cofinanciar (art. 74.3). Por Real Decreto, previa consulta con las Comunidades autónomas, se regulará el funcionamiento del Fondo para el patrimonio natural, que garantizará la participación de las mismas, singularmente en todos aquellos objetivos del Fondo que incidan sobre sus competencias. Se regirán por su normativa específica las ayudas de desarrollo rural para actividades agrícolas, ganaderas y forestales, así como la regulación de la condicionalidad de las ayudas de la Política Agraria Común (PAC), si bien en aquellas cuestiones que afecten a los espacios protegidos de la Red Natura 2000 o al cumplimiento de la Directiva 79/409/CEE del Consejo, de 2 de abril de 1979, relativa a la conservación de las aves silvestres, y de la fauna y flora silvestres. 
el sector empresarial turístico y en alianza con el sector social de la conservación y la custodia del territorio. Asimismo, abunda en la necesidad de mejorar la colaboración entre las administraciones turísticas y ambientales, así como con el sector privado y el resto de interesados, para integrar adecuadamente la biodiversidad en la oferta de turismo de naturaleza, con requisitos que sirvan para protegerla, conservarla y, al mismo tiempo, enriquecer la experiencia turística. En este sentido, la custodia del territorio puede contribuir a las alianzas entre los diferentes actores interesados de cara a avanzar en las sinergias positivas entre turismo, biodiversidad y conservación.

\section{CUSTODIA MARINA}

La custodia del territorio requiere de un desarrollo normativo al que ya nos referimos en otro lugar, al que nos remitimos ${ }^{31}$, más ahora procede dar cuenta de los retos adicionales que plantea la custodia aplicada al medio marino, que está comenzando a dar los primeros $\operatorname{pasos}^{32}$.

31 Me refiero a la colaboración "Custodia del territorio y bancos de conservación", en el libro Derecho ambiental para una economía verde, SANZ LARRUGA, FJ. (coord.), Aranzadi, 2016 (con SANTIAGO M. ÁLVAREZ GARREÑO, LUGÍA GASADO CASADO, ELISA PÉREZ DE LOS COBOS HERNÁNDEZ, GARLOS JAVIER DURÁ ALEMAÑ, JOSÉ RAMÓN SALGEDO HERNÁNDEZ, EDUARDO SALAZAR ORTUÑO, MARZIA SCOPELLITI), págs. 311-382, realizado en el marco del Proyecto de investigación: Red sobre "Mercado y medio ambiente. Propuestas jurídicas para una economía verde" ECOVER, Xunta de Galicia, 2014-2017, coordinado por Javier Sanz Larruga. (http://www.edu.xunta.es/web/node/13666.

32 Son muy numerosas ya las experiencias que nos ofrece el derecho comparado. En Jordania encontramos un ejemplo de gestión delegada de áreas protegidas. La responsabilidad nacional de las áreas protegidas ha sido delegada por el Estado a la ONG Real Sociedad para la Conservación de la Naturaleza (RSCN), que cuenta con financiación pública y privada, la cual proviene del pago por servicios ambientales, esto es, del pago de los usuarios de cuotas por entradas, zonas de acampada, comida y bebidas, sendas y actividades, así como de la producción y comercialización de productos naturales y artesanía de la zona. Por su parte, ya en el ámbito de la gestión de las áreas marinas, las islas del Caribe de Donaire y Saba (en las Antillas Holandesas) pagan el 100\% de los costes de explotación de sus áreas marinas protegidas con los ingresos del buceo. También en la costa del Mar Rojo en Egipto. En Italia, la Reserva Marina de Miramare depende del Ministerio de Medioambiente Italiano, pero la gestiona WWF Italia. Está financiada en un $75 \%$ por el Ministerio, el resto se autofinancia con las cuotas de entrada y por actividades. Hay ejemplos de concesiones en numerosos parques italianos, como los Parques Nacionales de Abruzzo, Gran Sasso y Cilento Vallo di Diano; y Maremma, entre otros. Es la solución que se ha adoptado en Cataluña en el caso de Aiguamolls del Ampurdán, Cabo de Creus, Delta del Ebro, entre otros. También es el caso de la reserva marina de las Islas Medas (Cataluña). Un ejemplo de custodia marina es el Sistema estadounidense de Santuarios Marinos Nacionales. Se trata de la experiencia de gestión de áreas marinas off-shore. más importante: los Santuarios Nacionales Marinos (National Marine Sanctuaries).

Con la aprobación de la Marine Resources and Engineering Development Act, se creó la "Comisión de Ciencias del Mar, Ingeniería y Recursos Naturales" "Comisión Stratton". Que concluyó la creación de la Administración Nacional Oceánica y Atmosférica (National Oceanographic Atmospheric Administration -NOAA así como el establecimiento de un programa nacional de gestión de las zonas de litoral, viendo la luz la Ley de Manejo de Zonas Costeras (Coastal Zone Management Act -CZMA) de 1972 y la Ley: la Ley de Protec- 


\section{Concepto y reflexiones sobre los retos adicionales que plantea la custodia aplicada al medio marino}

Como sucede en relación con el medio terrestre, la gestión pública del medio marino puede encontrar en la custodia marina una herramienta complementaria a las herramientas tradicionalmente aplicadas a este medio para su conservación y protección, especialmente la institución del dominio público, así como las zonificaciones y planificación ambiental, entre otras. Debe quedar claro que la custodia marina en ningún caso debe sustituir sino complementar la gestión pública que se deriva de la naturaleza demanial del medio en el que se desenvuelve y de la obligación pública de conservación del mismo como bien integrante del concepto de medio ambiente ex art. 45 de la CE.

Dicho lo anterior, debemos preguntarnos qué se entiende, en una primera aproximación, por custodia marina. Puede afirmarse que la custodia marina constituye una estrategia de conservación que intenta generar la responsabilidad de las Administraciones competentes y de los usuarios del medio marino en la conservación de sus valores naturales, culturales y paisajístico.

Además de las debilidades que la custodia plantea con carácter general, cuando la aplicamos esta novedosa técnica de intervención ambiental al medio marino se presentan una serie de retos adicionales sobre los que es preciso que nos detengamos ahora.

Estos retos, como puede deducirse -y que también se dan cuando esta técnica se aplica al dominio público hidráulico (custodia fluvial)-, se derivan de la propia naturaleza jurídica del medio marino como bien demanial en todo caso y, en ocasiones, fuera del ámbito de aplicación de algunas normas internas. Así, deben observarse las diferentes zonas marinas y el distinto ámbito de aplicación de las más importantes

ción e Investigación Marina de los Santuarios (Marine Protection, Research and Sanctuaries Act). El Título III de esta Ley fue más tarde renombrado como la National Marine Sanctuaries Act (NMSA). A partir de este marco normativo se creó el Sistema Nacional de Santuarios Marinos, integrado por 14 áreas marinas protegidas que abarcan más de 150.000 kilómetros cuadrados, incluyendo las costas cercanas a los arrecifes y alta mar, las riberas y los cañones marítimos, las zonas intermareales y bahías protegidas. En la gestión de los Santuarios Nacionales Marinos se persigue involucrar a los diferentes "usuarios" de dichos espacios protegidos con el fin de no separar lo que deba ser el desarrollo económico de la zona, siempre sostenible, de la conservación de dichos espacios, realizando ambos de manera cooperativa Vid. OLSEN, S., LOWRY, K., y TOBEY, J. “A Manual for Assesing Progress in Coastal Management", Coastal Management Report, núm. 2211, the University of Rhode Island. 1999; GÓMEZ PINA, G. La gestión integral de la Costa en los Estados Unidos: aspectos positivos a considerar en el modelo español. Comunicación presentada en el I Congreso de Ingeniería Civil, Territorio y Medio Ambiente. 2010. Santuario Nacional Marino de Monterrey y ALONSO GARCÍA, E.: "El Conocimiento y la Aplicación del Derecho Ambiental, un ejemplo práctico de Áreas Marinas Protegidas, en especial las Áreas Protegidas en el Mar Abierto", en J.L. PIÑAR MARIAS (Coordinador), Desarrollo Sostenible y Protección del Medio Ambiente, (Editorial Civitas, 2002). 
normas que inciden en el mar para poder diseñar el régimen jurídico de la custodia en cada una de ellas. Asimismo, deben tenerse en cuenta las dificultades que derivan de la propia naturaleza física del mar, menos explorado que el medio terrestre, así como de las especiales características de los ecosistemas en este tipo de ambientes.

En relación al primero de los retos apuntados, a diferencia de lo que sucede en el medio terrestre, la custodia marina se enfrenta al encaje de este instrumento jurídico de conservación con la inexistencia del régimen de propiedad en el mar, salvo en ciertos países como es el caso de Estados Unidos de América. Así, en una primera aproximación, como sucede en el ámbito de la custodia fluvial, la ausencia de propiedad privada pudiera parecer un inconveniente insalvable para la aplicación de la custodia al medio marino.

Recordemos que de los posibles sujetos que pueden intervenir en la custodia, las entidades de custodia, resultan de inexcusable presencia. Además, la custodia puede constituirse sobre otros derechos distintos del derecho de propiedad, como el derecho de uso, el derecho de explotación, y todos aquellos que, en general, pueden constituirse sobre bienes de dominio público. Así, pueden participar en la custodia marina tanto las AAPP como los usuarios (pescadores, clubes náuticos, buceadores, bañistas, etc.), que serán los agentes clave para la implementación de las medidas de conservación.

Sentado que jurídicamente es posible aplicar esta novedosa técnica de conservación al medio marino, a pesar de su carácter demanial, debemos referirnos ahora, ya en el plano científico, a algunas dificultades que se plantean en el ámbito marino, como consecuencia de sus características físicas. En efecto, debe tenerse en cuenta que el medio marino difiere, sustancialmente, del terrestre en la naturaleza de sus ecosistemas. Mientras que los científicos clasifican los ecosistemas terrestres según sus formas de vida vegetal dominantes, la clasificación de los ecosistemas acuáticos se basa fundamentalmente en las características del ambiente físico. Estos dos aspectos deben ser tratados inicialmente, para entender adecuadamente el espacio en el que se desarrollarán los acuerdos y las acciones o actividades propias de la custodia marina.

Volviendo al régimen jurídico de la custodia marina, debe tenerse claro que las entidades de custodia del medio marino, como las que operan en el medio terrestre, deben cumplir con los requerimientos legales que se derivan de la LPNB y, en consecuencia, deben ser organizaciones sin ánimo de lucro que promuevan acuerdos voluntarios con los usuarios y las Administraciones competentes (en este caso el Estado y, en su caso, las CGAA, porque como vimos ambas AAPP ejercen competencias en el medio marino). A su vez, podrán ser entidades de custodia marina asociaciones, fundaciones, etc. y entidades públicas (ayuntamientos, consorcios y otros entes públicos). 
El ámbito físico o territorial de actuación de la custodia marina se considera todo el medio marino, incluyendo las aguas de transición y la parte terrestre de dominio público marítimo terrestre, ya que tiene la misma singularidad que el mar y, además, será la regla general cuando se trate de áreas marinas de competencia autonómica, para garantizar la continuidad ecológica del espacio marítimo a custodiar, en la línea de la Gestión integrada del litoral y de conformidad con la propia LPMM. No obstante, podría plantearse una custodia internacional que podría ser objeto, entonces, de un convenio internacional, cuando el medio físico sobre el que se contemplara la custodia excediera de los límites de la Jurisdicción del Estado, pero esta cuestión, excede ahora nuestro ámbito de estudio.

La custodia marina, como la custodia aplicada al territorio, se fundamenta en el principio de voluntariedad de todas las partes implicadas en su aplicación: sociedad civil, sector privado pesquero y marino, y AAPP, aunque deben desarrollarse mecanismos que garanticen la continuidad y perpetuidad de los acuerdos, para que no resulte un fraude desplegar una actividad pública de fomento a través de ayudas y subvenciones para la conservación.

Pero, ¿qué entendemos por acuerdos de conservación en el medio marino en la práctica? Se entiende por acuerdo de custodia marina cualquier acuerdo dirigido a alcanzar objetivos de conservación en el medio marino, en los que una o más partes (usualmente titulares de derechos) se comprometen voluntariamente a emprender ciertas acciones, abstenerse de otras, o transferir ciertos derechos y responsabilidades a cambio de que una o más de las otras partes (entidades de conservación-custodia) se comprometan voluntariamente a entregar incentivos económicos explícitos (directos o indirectos). Cuando la conservación y restauración de un espacio, como interés público, es un valor añadido a una actividad económica, como la turística e incluso la pesquera, simplemente la mejora generada, como beneficio o valor difícil de cuantificar, puede servir de incentivo para el cumplimiento de las limitaciones que deriven del compromiso voluntario de custodia, sin necesidad, pues, de despegar incentivos económicos explícitos y quizá bastando con la prórroga de los títulos de uso y/o explotación que amparen las actividades económicas de referencia. Se trataría de compensar como plusvalías de uso, las externalidades positivas para la conservación del medio marino que suponen el cumplimiento del acuerdo de custodia.

\section{Análisis de un caso: las Marismas de Alday. La concesión como título habilitante}

En las Marismas de Alday, en Cantabria, se puede dar cuenta de una interesante experiencia de custodia marina ${ }^{33}$. Fundación Naturaleza y Hombre $(\mathrm{FNyH})$ ges-

33 Más información en http://www.fnyh.org 
tiona parte de estas marismas en los términos municipales de Camargo y Santander, mediante dos acuerdos de custodia, firmados con dos de las entidades públicas que tienen competencias o titularidad de derechos de gestión. Por un lado, con la entidad de competencia estatal, en este caso, con la Demarcación de Costas en Cantabria, ya que la zona central de las marismas forma parte del Dominio Público Marítimo Terrestre. Por otro, con la entidad competente a nivel local, el Ayuntamiento de Camargo. Junto a los terrenos públicos, existen propiedades privadas y otras pertenecientes al Ayuntamiento de Camargo. Los acuerdos se circunscriben a una superficie de 70 has. del humedal situado al oeste de la Bahía de Santander.

Este humedal es alimentado por aguas salinas procedentes de la Ría y el Canal de Raos, aunque también presenta aguas dulces y salobres. La actividad de custodia consiste en la restauración ecosistémica del espacio, con actuaciones de revegetación y gestión del hábitat, así como actividades de concienciación y divulgación. Ambos acuerdos tienen una duración de 30 años para garantizar un adecuado desarrollo y finalización de los proyectos de conservación previstos. Las externalidades positivas en este caso derivan de la recuperación de este espacio periurbano altamente degradado, lo cual supone la posibilidad de disfrute público de un espacio natural litoral.

Vemos, pues, con este ejemplo, que no todo acuerdo de custodia marina tiene por qué realizarse en mar abierto, sino que existe una gran oportunidad de avanzar en la gestión integrada del litoral llevando a cabo acuerdos de custodia en este tipo en zonas intermareales y litorales, ya que, en éstas, por lo general, se concentra una gran cantidad de población, lo cual puede generar efectos muy positivos en materia de conservación.

Por lo que se refiere al que hemos denominado acuerdo con la Demarcación de costas, debe aclararse que, para la formalización del acuerdo de custodia, en este caso ha sido necesario otorgar una concesión condicionada al cumplimiento de un proyecto de restauración aprobado por la Administración competente, tal y como contempla la legislación de costas, al afectar al uso del dominio público marítimo terrestre.

El iter procedimental seguido, aprovechando las técnicas jurídicas clásicas de intervención del dominio público marítimo terrestre fue el siguiente.

- La iniciativa para el desarrollo de un plan de restauración partió de la Fundación Naturaleza Hombre, la cual solicitó la concesión de ocupación de unos 117.735 m2 de dominio público marítimo-terrestre a la Demarcación de Costas de Cantabria para la realización de las obras de restauración comprendidas en el Proyecto de restauración de las "Marismas de Alday" que acompañó a la solicitud de concesión. 
- Sometida la petición a información pública y a informe de los organismos públicos implicados, concretamente la Consejería de OOPP y urbanismo, RENFE - por afectar el proyecto a la zona de influencia del ferrocarril-, la demarcación de carreteras y la Consejería de medio ambiente, la Demarcación de Costas, recibidas todas las alegaciones presentadas remitió el expediente a la Dirección General de costas del Ministerio con competencias en medio marino, poniendo de manifiesto que dada la degradación del espacio, resultaría positivo ejecutar el proyecto que planteaba la Fundación, con los condicionamientos que las AAPP competentes estimasen.

- La Demarcación de Costas finalmente accede y otorga la concesión en 2001, durante 30 años, sin perjuicio de la posibilidad de rescate de la misma de conformidad con el derecho público patrimonial.

Interesa destacar a la vista de este loable ejemplo de custodia marítimo-terrestre, varias cuestiones jurídicas, algunas de las cuales fueron en este caso objeto de discusión.

Por una parte, se plantea la eventual necesidad de sometimiento del proyecto de restauración a EIA. En este caso se entendió que no era necesario someter el proyecto a EIA, pero ello dependerá de las actividades de custodia que se pretendan desarrollar. Asimismo, cuando las actividades puedan afectar a espacios Red Natura 2000, será necesaria la evaluación ambiental en todo caso.

Otra cuestión a discutir será la duración de la concesión, ya que, si la financiación de la actividad de custodia proviene de la actividad de fomento de las AAPP, las concretas ayudas o subvenciones que financien la actividad de custodia de que se trate pueden estar condicionadas al mantenimiento durante un prolongado período de tiempo de los títulos habilitantes para el uso y ocupación.

En tercer término, aunque no se planteó en este caso, deben efectuarse algunas consideraciones en relación con la necesaria concurrencia que, en caso de concesiones de uso de dominio público, debería haberse promovido ${ }^{34}$, de modo similar a como se regula por el Real Decreto Real Decreto1028/2007, de 20 de julio, por el que se establece el procedimiento administrativo para la tramitación de las solicitudes de autorización de instalaciones de generación eléctrica en el mar territorial, cuestión a la que dedicamos un epígrafe especial a continuación.

34 Así se hizo en relación a un proyecto promovido a instancia particular fallido de restauración a coste cero de la Bahía de Portman. En este caso, temporalmente se abandonó el proyecto público de restauración, a día de hoy retomado, que supone una adjudicación con aplicación de la legislación sobre contratos del sector público, por un proyecto privado que requería actuaciones en el dominio público marítimo terrestre. 


\section{Propuesta conclusiva: adicionalidad y necesidad de garantizar la concurrencia en las concesiones de dominio público marítimo terrestre como título habilitante para la custodia marina}

Como ya advertimos, una vez que se despierta el interés de los usuarios por desarrollar actividades de custodia, debe quedar claro que siempre deben consistir en compromisos adicionales a las obligaciones que en su caso se deriven de la normativa aplicable. Además, la formalización del compromiso o acuerdo de custodia debería ser elaborado de común acuerdo con la entidad de custodia, siempre sin ánimo de lucro de conformidad con la LPNB. Una vez consensuado, se procedería a su validación -contando o no con el auxilio de entidades colaboradoras independientes- y, posteriormente a la aprobación del proyecto por la Administración competente. Esta iniciativa podría concluir, incluso, con la declaración de un área marina de interés privado, en el caso de que en el futuro se contemplara esta figura en la normativa sobre áreas marinas.

En el caso de que el acuerdo de custodia marina, esto es, dichos compromisos adicionales en el medio marino, afectaran a una AMP ya declarada -integrante o no de la Red Natura 2000-, que formara entonces parte de la RAMPE, la validación del acuerdo podría y, en puridad, debería suponer la modificación de su plan de gestión, en caso de estar ya aprobado, el cual incorporaría el contenido del acuerdo, salvo que estas acciones ya estuvieran contempladas en el mismo como acciones adicionales y, por tanto, voluntarias. Es por ello muy importante que quede clara dicha adicionalidad y que no se utilice la custodia, terrestre o marina, en nuestro caso, para enmascarar obligaciones derivadas del régimen jurídico de los espacios naturales.

Este diseño que proponemos admite algunas variantes, como, por ejemplo, incluir en la tramitación de la declaración de las $\mathrm{AMP}_{\mathrm{S}}$ la participación de entidades de custodia en todo caso y requerir la previa certificación de las entidades de custodia por entidades colaboradoras, previamente acreditadas por la Administración.

Dicho lo anterior, como hemos anunciado, además de la validación del proyecto-acuerdo de custodia marina, cuya conformidad a derecho debe ser evaluada por la Administración competente para la aprobación del mismo, será necesaria la intervención, en todo caso, de la Demarcación de costas, pues cualquier actuación en el medio marino que suponga su uso, ocupación o explotación requerirá la correspondiente concesión de dominio público, como hemos visto en la experiencia cántabra descrita supra.

No obstante, a nuestro juicio, para otorgar este tipo de concesiones, cuando el promotor del proyecto en que consiste la actuación de custodia sobre el medio marino resulte ser un particular, debería haberse convocado públicamente la adju- 
dicación mediante concurso de la concesión demanial, como tuvo lugar en el caso de Portman (Resolución de la Dirección General de sostenibilidad de la costa y del mar por la que se publica la convocatoria para la adjudicación mediante concurso de una concesión para la ocupación del dominio público marítimo terrestre para el aprovechamiento minero de la bahía de Portmán) ${ }^{35}$. Cosa distinta, en cambio, sería un proyecto público, cuya ejecución se somete a concurrencia en aplicación del TRLCSP, como al final ha tenido lugar en el caso del proyecto de Restauración de la bahía de Portmán que se está ejecutando en la actualidad, en cuyo caso no sería necesaria la concurrencia para el otorgamiento de la concesión demanial pertinente.

Así pues, en el caso de que la actividad de custodia marina sea propuesta por el sector privado, proponemos como modelo el acogido por el Real Decreto 1028/2007, de 20 de julio, por el que se establece el procedimiento administrativo para la tramitación de las solicitudes de autorización de instalaciones de generación eléctrica en el mar territorial.

En aplicación de dicho Reglamento, aquel que pretenda obtener una autorización para la instalación de un PEM, de modo previo necesitará contar con el otorgamiento de la reserva de zona. Para ello, formulará la solicitud para la realización de los estudios previos a la solicitud de autorización de la instalación, junto con el estudio de impacto ambiental de este proyecto de investigación (art. 7 RDPEMT). Con anterioridad al acuerdo de iniciación del procedimiento de concurrencia, previo al otorgamiento de la reserva de zona, es necesario que exista una caracterización de área eólica marina vigente sobre el área solicitada. Si no existiera, o se previera que su vigencia no se fuera a extender hasta la resolución del procedimiento de concurrencia ${ }^{36}$, la DGPEM procederá a iniciar el procedimiento de caracterización de la misma (art. 9). La caracterización del área eólica marina se hará pública en el BOE y en la página web del Ministerio de Industria, Turismo y Comercio, mediante un anuncio en el que se indicará la existencia de dicho documento de caracterización y los datos referentes a los lugares donde pueda consultarse como la DGPEM del Ministerio de Industria, Turismo y Comercio y la Delegación de Gobierno de la Comunidad Autónoma lindante con el área caracterizada (art. 13). En el mismo anuncio se convocará la apertura del procedimiento de concurrencia regulado en los arts. 14 y sucesivos. Este procedimiento de concurrencia tendrá como ámbito de aplicación la totalidad del área eólica marina para la cual se realizó la solicitud, y cualquier promotor interesado pueda concurrir con un proyecto de instalación de PEM en el área solicitada. De este modo, además de quien solicitó la reserva de zona, pueden concurrir otros

35 BOE de 4 de abril de 2014.

36 Téngase en cuenta que la caracterización de área eólica marina, en virtud del art. 13 del RDPEMT, tiene una vigencia de 5 años, contados a partir del día siguiente al de la publicación del anuncio de la misma. 
promotores. Cuando sólo exista una solicitud, o los proyectos presentados no se solapen, se elevará propuesta favorable de resolución, de tantas reservas de zona como proyectos existan, siempre y cuando las condiciones para la autorización del proyecto o proyectos de las instalaciones eólicas marinas sean las adecuadas ${ }^{37}$.

A nuestro juicio, se trata de un modelo idóneo para resolver los conflictos de intereses que pueden surgir entre eventuales promotores de proyectos de custodia marina.

37 Si el Comité de Valoración lo estima conveniente, convocará una fase de audiencia pública a los interesados, en el caso de que existan proyectos que se solapen o cuando la suma de las potencias solicitadas superen el límite establecido por el operador del sistema o gestor de la red de transporte en la caracterización de área eólica marina, con el fin de que los solicitantes puedan, en el plazo de un mes, modificar sus propuestas o presentar una propuesta conjunta eliminando así el solapamiento o reduciendo sus potencias hasta el límite máximo establecido. El Comité de Valoración elevará la propuesta de resolución al Secretario General de Energía para su consideración, antes de que transcurran tres meses desde la finalización del período de recepción de solicitudes, quien dictará resolución antes de que transcurra un mes desde la fecha de la propuesta. En nuestra opinión, y aunque no se establezca expresamente, la resolución del órgano competente, esto es, del Secretario General de Energía, podrá apartarse del sentido de la propuesta de resolución elaborada por el Comité de Valoración, motivando esta circunstancia en los supuestos en que el órgano competente llegue a otra conclusión de la aplicación de los criterios a que se refiere el art. 16 del RDPEMT, por fuerza mayor, modificación normativa de cuya aplicación resulte contrario a la norma el sentido de la propuesta, desistimiento de algún solicitante o por cualquier otra causa de interés público debidamente justificada. Finalmente, la resolución del procedimiento de concurrencia y otorgamiento de la reserva de zona serán notificados a los interesados y remitidos al BOE y al Boletín Oficial de la Provincia o Provincias afectadas por el proyecto para su publicación, en el plazo de un mes desde la fecha de la misma (art. 17).

La resolución hará referencia a los siguientes aspectos. En primer lugar, indicará el proyecto o proyectos seleccionados de las solicitudes presentadas, con referencia a su promotor o promotores y un resumen de sus características. En segundo lugar, justificará dicha selección con base en los criterios a que se refiere el art. 16 del RDPEMT y a los criterios adicionales que, en su caso, se hayan establecido. Por último, llevará a cabo una atribución, para cada uno de los solicitantes seleccionados, del derecho de la reserva de zona correspondiente a la poligonal para la cual se presentó el proyecto, por un período de dos años, con carácter de exclusividad. De acuerdo con el art. 18 del RDPEMT, el solicitante que haya obtenido la reserva de zona deberá depositar un aval adicional por importe del 1 por 100 del presupuesto de su proyecto.

Asimismo, con la resolución del procedimiento de concurrencia se le otorgará al solicitante o solicitantes seleccionados un derecho de acceso a la red de transporte por la potencia asignada en dicha resolución, que podrá ser revocado en el caso de no llevarse a cabo la instalación en los términos previstos. La resolución se remitirá entonces a la Dirección General de Calidad y Evaluación Ambiental para iniciar la EIA del proyecto, junto con la información necesaria, aportada por el promotor, así como a la Dirección General de Costas, para tramitar el procedimiento de concesión para la ocupación del dominio público marítimo-terrestre cuando se cumpla con todos los requisitos exigidos por la LG y a la Dirección General de Marina Mercante. De este modo, a la DIA seguirá la autorización de instalación y a ésta la concesión de ocupación del dominio público marítimo-terrestre. No obstante, destacar que la concesión de la ocupación del dominio público marítimo-terrestre requerirá la autorización de la Dirección General de la Marina Mercante, del Ministerio de Fomento, cuando puedan verse afectadas la seguridad marítima, la navegación y la vida humana en el mar. 
Además, tendría más sentido esperar a la obtención de la concesión de ocupación de dominio público marítimo-terrestre para resolver el procedimiento de autorización de los proyectos que inciden en el mar, ya que no se entiende que un titular obtenga una autorización para la realización de cualquier actividad de custodia marina, sobre un área sobre la que, después no no se obtenga la concesión de ocupación del dominio público marítimo-terrestre. 


\section{BIBLIOGRAFÍA:}

ALONSO GARCÍA, E., "El Conocimiento y la Aplicación del Derecho Ambiental, un ejemplo práctico de Áreas Marinas Protegidas, en especial las Áreas Protegidas en el Mar Abierto", en J.L. PIÑAR MARIAS (Coordinador), Desarrollo Sostenible y Protección del Medio Ambiente, Civitas, 2002.

BERMEJO LATRE, J. L., "La participación del público en la protección de la biodiversidad", Monografías de la Revista Aragonesa de Administración Pública, XVI, Zaragoza, 2016, págs. 169-171.

FUENTES GASÓ, J. R., Avances en la protección y conservación del medio marino español. El nuevo marco para la ordenación del espacio marítimo, Revista Catalana de Dret Ambiental Vol. VIII Núm. 1 (2017).

FUERTES LÓPEZ, M., "Los convenios y los consorcios en la Ley del Sector Público", conferencia impartida en el Seminari de Dret Local: les lleis 39 i 40 de 2015, de Procediment Administratiu i Règim Furídic del Sector Públic, Federación de Municipios de Cataluña, Barcelona, 20 de noviembre de 2015.

GÓMEZ PINA, G., La gestión integral de la Costa en los Estados Unidos: aspectos positivos a considerar en el modelo español. Comunicación presentada en el I Congreso de Ingeniería Givil, Territorio y Medio Ambiente, 2010.

MARTÍN MATEO, R., "Planificación ambiental oceánica", en Revista de Cestúin Ambiental, enero de 1999

MENENDEZ REXACH, A., "La ordenación del espacio marítimo", en NÚÑEZ LOZANO, M. C., Estudios jurídicos sobre el litoral, Tirant lo Blanch, Valencia, 2016.

MENÉNDEZ REXACH, A., Ordenación del litoral: una propuesta de revisión, Práctica urbanística: Revista mensual de urbanismo, núm. 137, 2015

MORENO GANOVES, A., Régimen jurídico del litoral, Tecnos, Madrid 1990.

OLSEN, S., LOWRY, K., y TOBEY, J. “A Manual for Assesing Progress in Coastal Management", Coastal Management Report, núm. 2211, University of Rhode Island, 1999.

PAREJO NAVAJAS, T., "Justificación del tratamiento integral de la costa y el mar próximo a través de la política marítima integrada", en FARiNós DASí, J., (ed. y coord.), La gestión integrada de zonas costeras ¿Algo más que una ordenación del litoral revisada? La GIZC como evolución de las prácticas de panificación y gobernanza territorial, PUV, Valencia, 2011--- La proyección de la ordenación física de usos sobre la costa y el mar próximo: la planificación del aquitorio, Iustel, Madrid, 2011. 
SANZ LARRUGA, J., "La nueva ordenación del espacio marítimo: Análisis del Real Decreto 363/2017, de 8 de abril”, Práctica urbanística, núm. 150, La Ley 275/2018.

SORO MATEO, B., et. al., Custodia del territorio y bancos de conservación, en Derecho ambiental para una economía verde: informe Red Ecover / coord. por Javier Sanz Larruga, Juan José Pernas García, Jennifer Sánchez González, 2016, págs. 311-382. 